\title{
Stress threshold identification of progressive fracturing in Bukit Timah granite under uniaxial and triaxial stress conditions
}

\author{
B. Lee $\cdot$ T. D. Rathnaweera
}

Received: 4 July 2016/Accepted: 19 August 2016/Published online: 7 September 2016

(C) Springer International Publishing Switzerland 2016

\begin{abstract}
This paper reports the results of an extensive study of the deformation and fracturing of Bukit Timah granite in Singapore under uniaxial and triaxial loading conditions. In the investigation, the stress fracturing thresholds (crack initiation, crack coalescence and crack damage) were determined using stress-strain and stiffness curves and the acoustic emission (AE) detection technique. Crack initiation was found to be best determined by the volumetric strain curve in both uniaxial and triaxial compression tests. The subjectivity of determining the crack closure region and these stress thresholds can be overcome and the results validated by the $\mathrm{AE}$ technique by simply observing the cumulative curve of the $\mathrm{AE}$ count plotted against deviator stress, which showed four distinctive zones of fracturing. Furthermore, AE detection in the loading stage was found to be a powerful method for determining the phenomena of stable and unstable crack propagation, which are helpful in predicting the rockburst phenomenon. Finally, a comprehensive petrographical analysis using a petrological microscope and a scanning electron microscope was performed to identify the
\end{abstract}

B. Lee

Golder Associates Pty Ltd, Melbourne, Australia

T. D. Rathnaweera $(\bowtie)$

Deep Earth Energy Laboratory, Department of Civil

Engineering, Monash University, Building 60, Melbourne,

VIC 3800, Australia

e-mail: tharaka.rathnaweera@monash.edu mode of cracking and the characterisation of the cracking pattern.

Keywords Uniaxial loading - Triaxial loading · Granite $\cdot$ Crack thresholds $\cdot$ Petrographical analysis

\section{Introduction}

Failure of underground openings in rocks is a function of the in-situ stress magnitudes and the characteristics of the rock mass, i.e., the intact rock strength and the discontinuity network (Hoek et al. 1995). In many major underground engineering projects, in cases where in-situ stresses are high and discontinuities play an insignificant role, stability analysis for the excavation openings typically involves a comparison between the state of stress surrounding the excavation and the intact strength of the host rock. The excavation of underground caverns causes deformation and redistribution of the in-situ stresses in rock, resulting in zones of induced stress concentrations around the caverns. As a result, strain energy increases in these zones due to the stress concentration. Moreover, an imbalance of energy is built up and if it is released, progressive degradation of the rock mass strength through stress-induced brittle fracturing occurs and may change the permeability of the near-field host rock. However, this brittle fracturing in rock may not only be induced at high stress levels as rockburst but 
also develops in brittle rock, usually at low stress levels (Stacey 1981). Therefore, an understanding of the fracture mechanism of rock is essential for the design of underground structure excavation methods to prevent failure of the surrounding rocks.

The deformation and fracture characteristics of brittle rocks have been studied by numerous researchers over the past 40 years. Among the proposed fundamental concepts of rock fracture, Griffith's theory (Griffith 1921) in elastic materials is the fundamental concept on which past and present research have been based. A Griffith's crack is a flaw which is approximately elliptical in shape. It is assumed that the fracture initiates from the boundary of an open flaw when the tensile stress on this boundary exceeds the local tensile strength of the material. Griffith's cracking scenario was later modified to account for the frictional effects due to crack closure in compression by McClintock and Walsh (1962). Brace (1964) and Bieniawski (1967a) later proposed the generally-accepted concept of a brittle rock failure mechanism, which extensively describes the brittle failure process as crack closure, crack initiation and crack propagation leading to failure. Brace and Bombolakis (1963) and Hoek and Bieniawski (1965) have demonstrated experimentally that a crack which initiates on the boundary of the elliptical flaw propagates out of the plane of this flaw. Hoek (1968) summarised the early research on brittle fracture behaviour of hard rock by Griffith (1921). Moreover, Hoek (1968) showed that since a fracture is assumed to occur when the tangential stress on the boundary of the flaw exceeds the local tensile strength of the material, it can be assumed that the crack will propagate in a direction which is normal to the boundary of the ellipse. It is strongly believed that the micro-cracking mechanism is initiated from preexisting cracks in rock which lead to macro-cracking failure. The initiation and propagation of cracks generate elastic waves in conjunction with energy release called acoustic emissions. Therefore, the study of acoustic emission (AE) allows the identification of the characteristics and correlates with the fracture mechanism. Lajtai and Lajtai (1974), Reyes and Einstein (1991) and Bobet and Einstein (1998) have studied extensively the cracking patterns of overlapping and non-overlapping flaws in gypsum plaster under confined and unconfined compression. Hoek's analysis of crack initiation and propagation based on
Griffith's theory was further supported by the studies by Reyes and Einstein (1991), Shen et al. (1995) and Bobet and Einstein (1998), who observed two types of crack patterns i.e., primary and secondary cracks in pre-existing fractures in gypsum specimens loaded in uniaxial and biaxial compression. However, as Brady and Brown (1994) commented, the use of Griffith's microscopic theory to predict the macroscopic behaviour of rock material under a variety of boundary conditions requires the introduction of a set of Griffith crack size, shape and orientation distribution functions which have not yet been defined.

The main objective of the present study is to investigate the deformation and strength characteristics and the fracturing characteristics of Bukit Timah granite, which has been identified as a potential rock for hosting future caverns in Singapore, under static loading conditions, in order to better understand the behaviour of the rock around excavation openings.

\section{Experimental methodology}

\subsection{Sample description}

Bukit Timah granite is part of a massive igneous batholith of early Triassic age in peninsular Malaysia. It is an extensive rock formation in Singapore, extending some $8 \mathrm{~km}$ in a northerly direction and $7 \mathrm{~km}$ in a westerly direction, where it forms hills and valleys of both high and low relief. It covers one third of the land area of the main island of Singapore (Central Singapore granite) as shown in Fig. 1, and the whole of Pulau Ubin (Pulau Ubin granite). The granite formation found in Singapore is overlain by sedimentary rocks of the Jurong Formation in western Singapore and by the Old Alluvium, a Quaternary deposit, in eastern Singapore. Bukit Timah granite is a general descriptive term for the entire suite of acid rocks including granite, adamellite and granodiorite, and the acid and intermediate hybrids mainly of granodioritic and dioritic composition, resulting from the assimilation of basic rock within the granite (Pitts 1984).

The Bukit Timah granite samples were obtained from core rock recovery from 11 boreholes at the investigation site in Mandai and the depth of the boreholes ranged from 80 to $100 \mathrm{~m}$. During sample selection, considerable care was taken to maintain the 


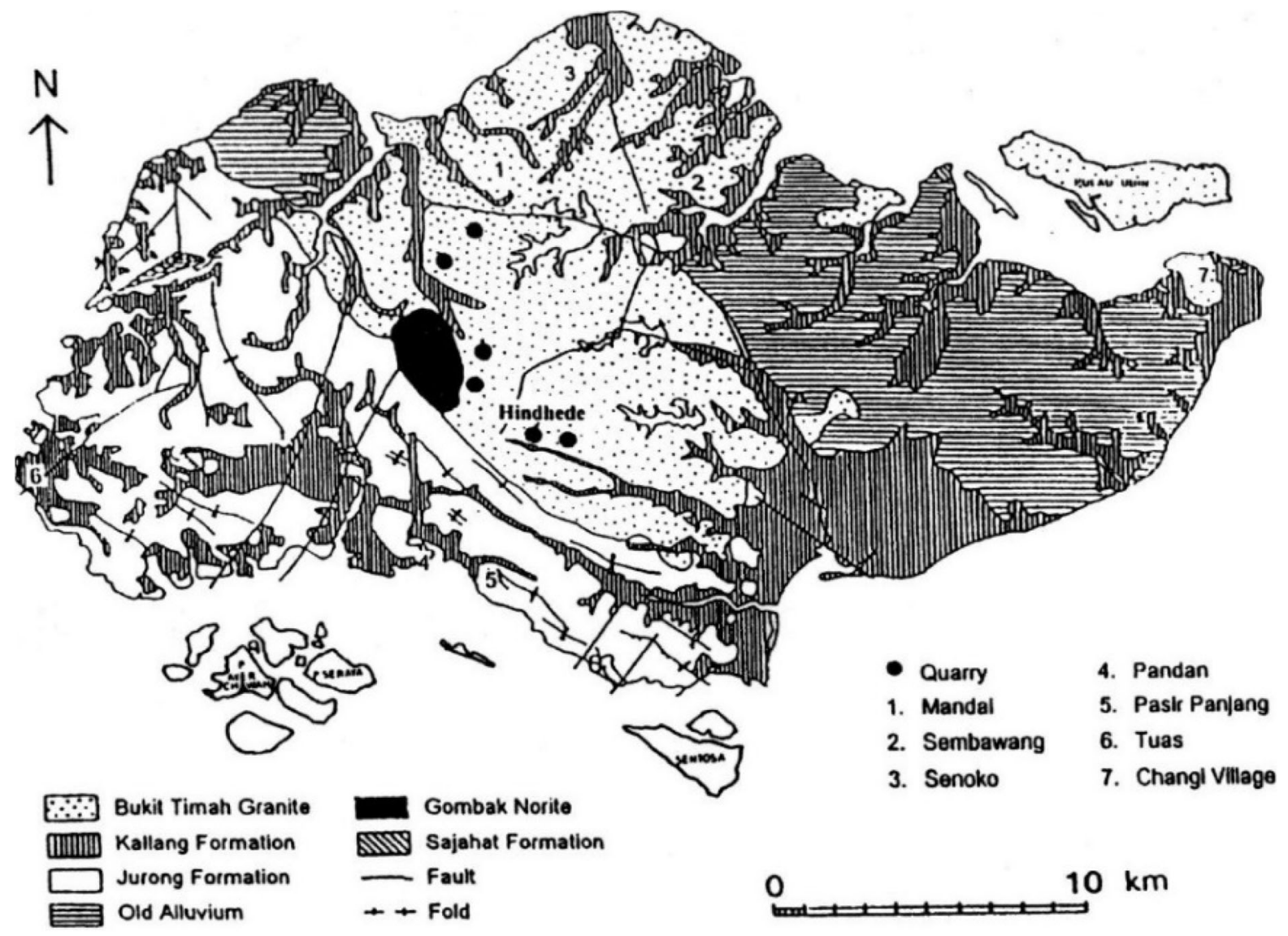

Fig. 1 Generalised geological map of Singapore Island (PWD, 1976)

consistency of test specimens, including the same mineralogy percentages of constituent minerals and freedom from visible joints (see Fig. 2). In order to maintain the mineralogical consistency of the test specimens, X-ray diffraction (XRD) analyses were performed and according to the XRD results, the mineral composition of this granite includes $97 \%$ quartz, $2 \%$ biotite, $1 \%$ feldspar, $<1 \%$ amphibole and $<1 \%$ other clay minerals with an average gain size of $2.0 \mathrm{~mm}$. In addition, Mercury intrusion porosimetry (MIP) tests were carried out to determine the porosity of the tested samples and the porosity was found to vary between 1 and $2 \%$.

\subsection{Preparation of rock core specimens}

Once samples had been selected, sample preparation was carried out according to the American Society of Testing and Materials Standards (ASTM D4543-85)

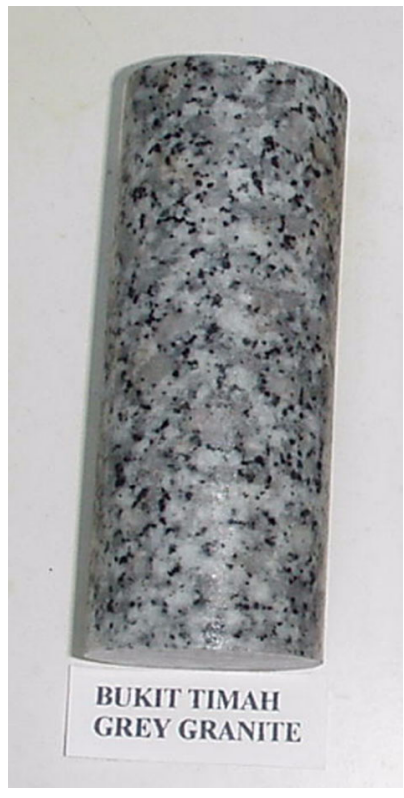

Fig. 2 Prepared rock specimen for testing 
and the International Society of Rock Mechanics (ISRM) suggested methods with length (L) to diameter (D) ratios $(\mathrm{L} / \mathrm{D})$ of approximately 2.5. The present study selected a $\mathrm{L} / \mathrm{D}$ ratio of 2.5 to maintain a constant apparent strength throughout the tests and this ratio has been shown by Mogi (1966) to be the critical ratio at which apparent strength becomes nearly constant.

\subsection{Compression machine}

A Stiff Test System STS-1000 compression machine was used for the strength tests, which is designed for static and dynamic closed-loop operation and is capable of performing strain- or stress-controlled as well as post-failure behaviour testing. It comprises a four-column testing frame, a load cell, a servocontrolled hydraulic actuator and a triaxial cell, as shown in Fig. 3.

The trixial cell (SBEL Rockcell Model 10) in this set-up is designed to accept NX size cores of $54 \mathrm{~mm}$ diameter and has a lateral confining pressure capacity of $138 \mathrm{MPa}$. During the compression tests, each sample was instrumented with four electric resistance precision strain gauges (two axial and two lateral) $40 \mathrm{~mm}$ in length to record sample deformation. Strain gauges were glued with $\mathrm{CN}$ adhesive directly to the cleaned sample surface to ensure a solid bond. The compression tests were performed using the advanced fatigue test software application Wavemaker, which has capabilities including block loading with a variety of mode changes, absolute or relative ramps, sines and other wave shapes. Finally, the internal data logging

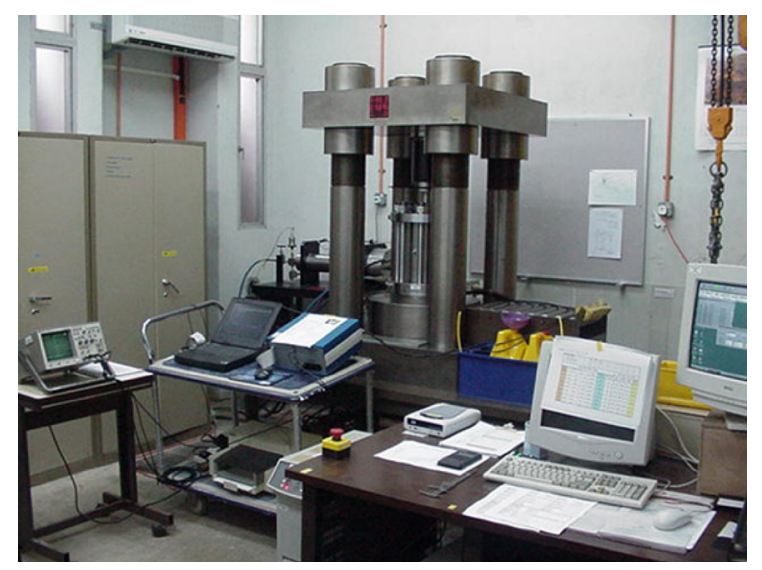

Fig. 3 Overview of triaxial compression testing system system Instron WavemakerRunner was incorporated to record the test data.

\subsection{Acoustic emission (AE) technique}

Generally, dislocation, grain boundary movement, or initiation and propagation of fractures through and between mineral grains in polycrystalline rock as a result of the sudden release of energy generate an elastic stress wave known as an acoustic emission (AE). AE is a naturally occurring phenomenon, which has been observed as rock noise in earthquakes and rockburst in mines since the early days (Drouillard 1996). With the invention of AE devices in the 1960s, research on the fundamentals of $\mathrm{AE}$ has led to the characterisation of $\mathrm{AE}$ behaviour and the development of instrumentation, and the correlation of AE activity with the failure mechanism. AE interpretation has been established as a non-destructive test (NDT) method and is developing into a mature stage. Over the years, waveform-based $\mathrm{AE}$ analysis has been shown to be a useful tool, especially in identifying the significant cracking of brittle rock by researchers such as Hardy (1981), Boyce et al. (1981), Fonseka et al. (1985), Eberhardt et al. (1998) and Ranjith et al. (2004).

The present study therefore used AE tests to understand the crack formation behaviour of Bukit Timah granite. In order to identify the crack growth and plastic deformation, AE system was coupled with the compression machine, as shown in Fig. 4. The AE system which was used for this experiment is called the AESMART2000. This system is designed to operate as a displacement-sensitive device in the 20-60 kHz range of frequencies, which corresponds to the low frequency flexure wave produced by out-ofplane sources, and as a velocity-sensitive device at frequencies above $100 \mathrm{kHz}$, which responds to the high frequency extensional waves produced by i-plane sources, and to the high frequency shear waves produced by both out-of-plane and i-plane sources. During AE testing, the detected signals of crack initiation and propagation are filtered into high frequency and low frequency channels. The amplitudes of the high frequency channel are detected and those surpassing the background threshold set at $500 \mathrm{mV}$ in the present study were counted as AE counts. The hardware includes two sensors and external amplifiers. In the uniaxial experiments, two 


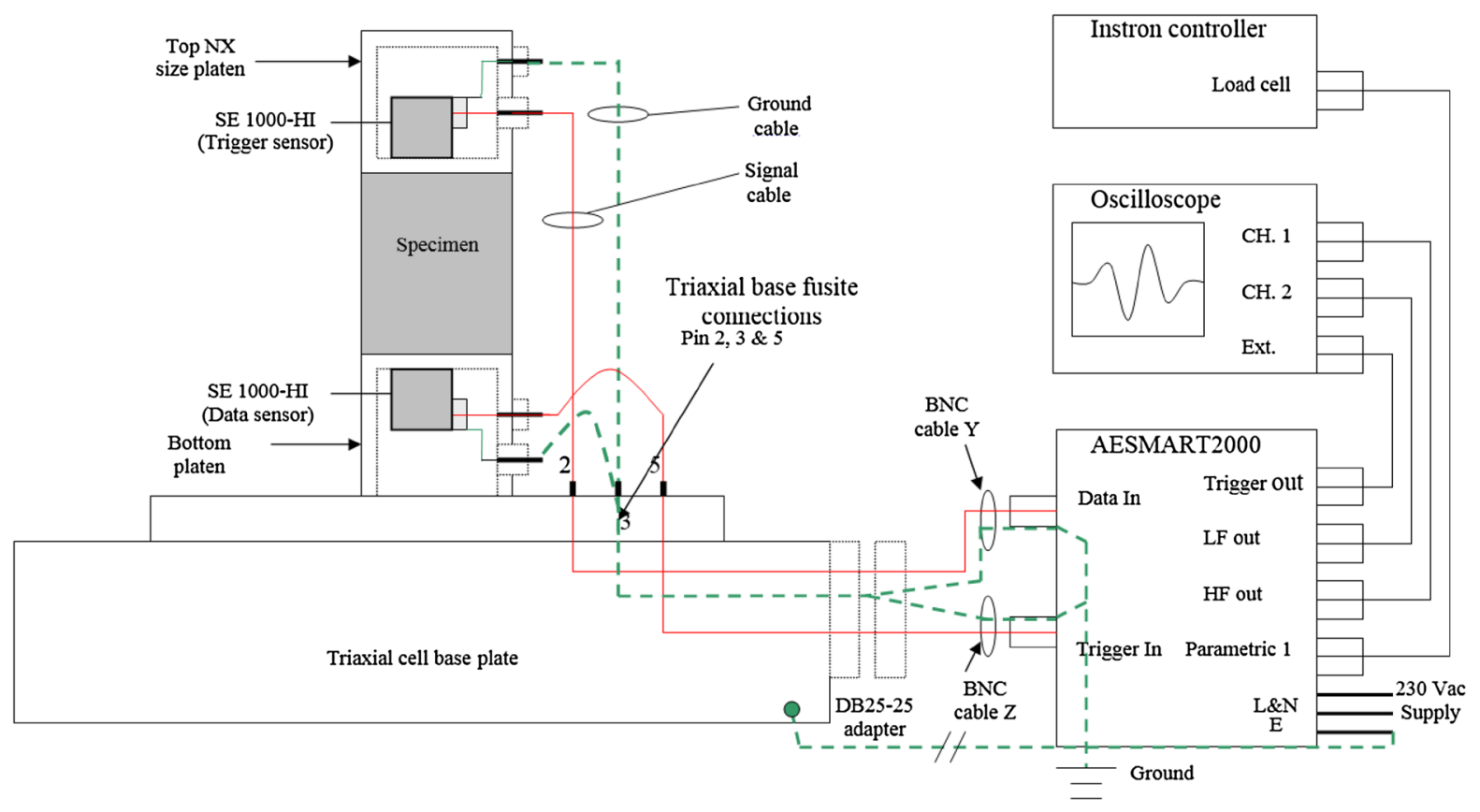

Fig. 4 Schematic diagram of the configuration of acoustic emission set-up

sensors were connected in series on either side of the sample and placed $10 \mathrm{~mm}$ below each face for effective data acquisition. However, in the triaxial experiments, these two sensors were mounted in series to the sample on either side of the pressure cell and placed $10 \mathrm{~mm}$ below each face. The amplifiers were used to amplify the low frequency acoustic waves resulting from the crack fracturing process in the rock and were set to $60 \mathrm{~dB}$ to amplify the AE signals. In order to detect any crack-like signals, the threshold of the high frequency channel was set slightly higher than background ambient noise level.

\subsection{Petrographical analysis}

Petrographical analyses were carried out on both unloaded (see Sect. 2.6) and loaded (stress-induced) samples. The mineralogy, mineral grain size and preexisting crack pattern of the Bukit Timah granite were studied under thin-section slides $(50 \mathrm{~mm} \times 20 \mathrm{~mm} \times$ $0.03 \mathrm{~mm}$ ) without being loaded, as shown in Fig. 5a. Under loading conditions, loaded specimens at different loading stages were cut in two halves along the long axis. Thin sections with a thickness of $30 \mu \mathrm{m}$ were then made from the central part of one of the halved cylindrical specimens where the stress is the most

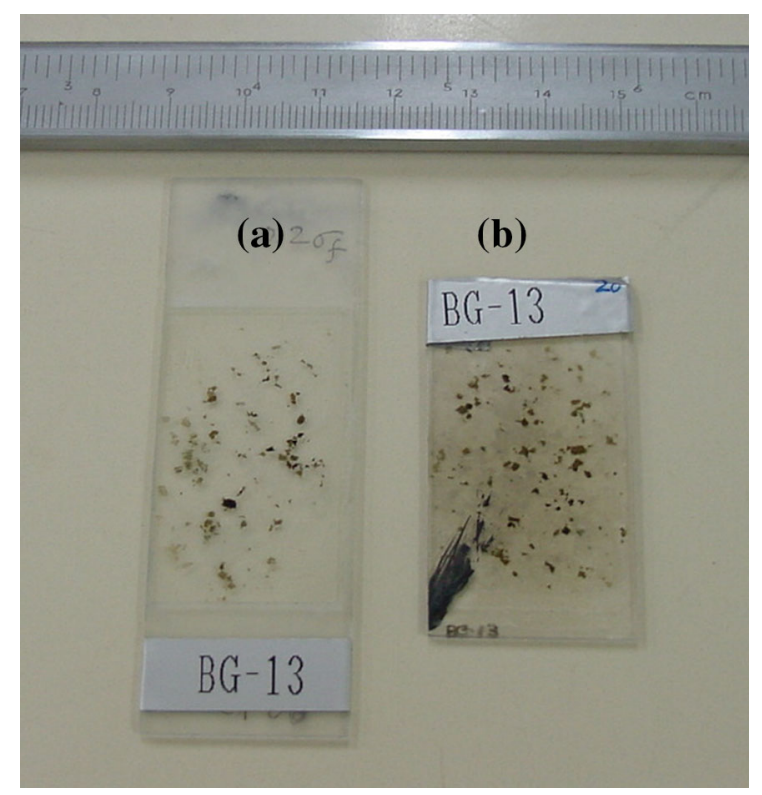

Fig. 5 Samples of thin section: a thin sections for petrological optical microscope, $\mathbf{b}$ carbon-coated thin sections for scanning electron microscope

uniform (Hallbauer et al. 1973). Finally, fractographic evolution was carried out in these sections using a petrological optical microscope at the scale of $0.1 \mathrm{~mm}$. 
In addition, SEM imaging using a Philips XL30 $\mathrm{LaB}_{6}$ solid-state back-scatter detector was used to study the crack growth at the scale of $0.001 \mathrm{~mm}$ in the specially-made thin sections coated with carbon (200A thickness). A prepared SEM thin-section specimen had a thickness of $30 \mu \mathrm{m}$, as shown in Fig. $5 \mathrm{~b}$.

\subsection{Experimental procedure}

The experimental series was initiated by performing uniaxial and triaxial compression tests monotonically in stress control mode on the Bukit Timah granite samples. For each condition, six replicates were used and the average values were considered for discussion with the standard deviation of $0.028 \%$. In triaxial compression tests, ascending confining pressures of 5 , 10, 20, 30 and $40 \mathrm{MPa}$ were applied, and here, $5 \mathrm{MPa}$ confining pressure approximately simulates the working conditions at a maximum depth of $100 \mathrm{~m}$. To monitor the fracture propagation, NDT AE detection was used, along with compression tests. Finally, petrographical analyses (including photomicrograph analysis and SEM) were carried out to study the development of micro-fracturing of cracks at different stages of loading and before loading.

The stress-strain behaviour of dry Bukit Timah granite was first investigated in the uniaxial stress environment and then in the triaxial stress environment under monotonic loading. When the monotonic loading was completed, a separate uniaxial experimental series was carried out under staged loading to better understand the mechanical behaviour of Bukit

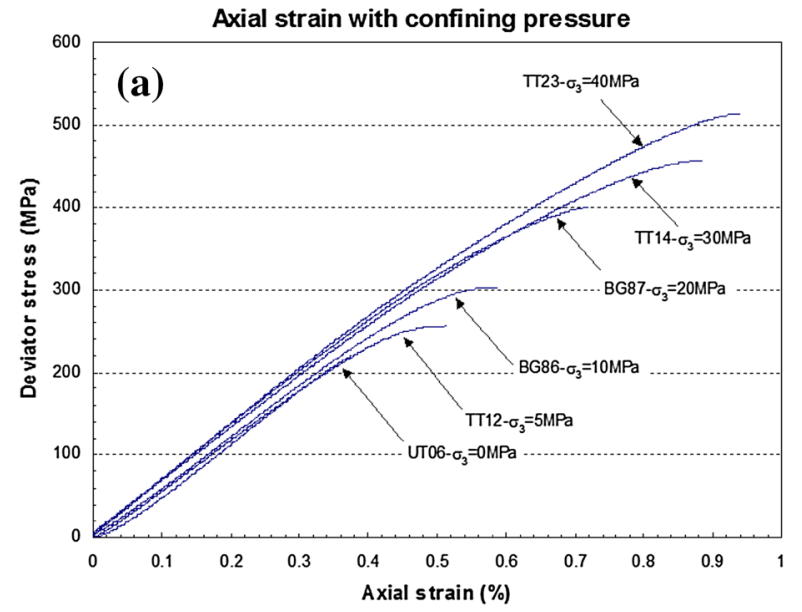

Timah granite. Under the staged loading, the specimen was first loaded to $0.45 \sigma_{f}$ and then unloaded to $0.20 \sigma_{f}$ and reloaded again to $0.60 \sigma_{f}$. In addition, the load was held at the $0.60 \sigma_{f}$ stress level for 3 min. Finally, load was unloaded back to $0.45 \sigma_{f}$ and reloaded to $0.85 \sigma_{f}$.

After finishing the compression tests on dry samples under both monotonic and staged loadings, a series of uniaxial compression tests on fully watersaturated granite samples under monotonic loading was conducted to evaluate the influence of moisture on the mechanical behaviour of Bukit Timah granite. This is important, because water saturation can change the mechanical properties of granite samples, significantly affecting major underground engineering projects.

\section{Results}

\subsection{Stress-strain behaviour}

Figure 6 shows the stress-strain behaviour of granite specimens under the different confining pressures of 0 (uniaxial), 5, 10, 20, 30 and $40 \mathrm{MPa}$. According to the results, the tested Bukit Timah granite samples show an average uniaxial compressive strength of $216 \mathrm{MPa}$. In addition, rock strength increases with increasing confining pressure and this behaviour is consistent with the typical stress-strain behaviour of brittle rock under confining stress conditions (Rathnaweera et al. 2015; Wasantha et al. (2015)). With respect to the unconfined stress condition, 45, 87, 113 and $137 \%$

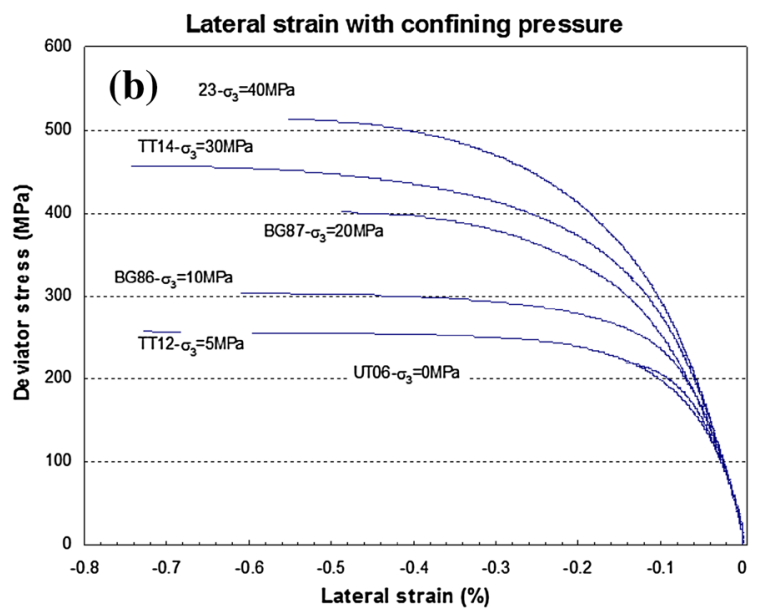

Fig. 6 Deviator stress versus a axial strain and $\mathbf{b}$ lateral strain curves for Bukit Timah granite 
failure stress increments were observed under confining pressures of 10, 20, 30 and $40 \mathrm{MPa}$, respectively. Moreover, the percentage strength increment decreased with increasing confining pressure, and a $42 \%$ strength increment was recorded as the confining pressure changed from 10 to $20 \mathrm{MPa}$. However, only $19 \%$ increment was observed when confining pressure changed from 30 to $40 \mathrm{MPa}$.

The maximum axial, lateral and volumetric strains of Bukit Timah granite under different confining pressures are summarised and tabulated in Table 1. As Table 1 shows, the average maximum axial strain increases with confining pressure. The average lateral strain also increases with increasing confining pressure, except at $40 \mathrm{MPa}$. The other important mechanical properties in relation to the mechanical behaviour of Bukit Timah granite are the Young's modulus and Poisson's ratio. The Young's modulus and Poisson's ratio were determined in the linear elastic deformation region, which is confined between the crack closure stress region and the crack initiation stress threshold (see Sect. 3.2). The average Young's modulus and Poisson's ratio of each confining pressure are summarised and plotted in Fig. 7. As can be seen in Fig. 7, Young's modulus appears to be independent of the confining pressures. It decreases slightly from 0 to about $10 \mathrm{MPa}$ confining pressure, but increases to the same level as the confining pressure increases from 10 to $20 \mathrm{MPa}$ and then remains constant at $64 \mathrm{GPa}$. A similar trend was observed for Poisson's ratio, as the Poisson's ratio decreases slightly with increasing confining pressure and stabilises after $20 \mathrm{MPa}$. For values of confining pressures less than $5 \mathrm{MPa}$, the Poisson's ratio appears to be constant at about 0.265 . A sharp decrease in the average values of Poisson's ratio from about 0.265 to about 0.213 occurs between

Table 1 Summary of maximum axial, lateral and volumetric strain

\begin{tabular}{llll}
\hline $\begin{array}{l}\text { Confining } \\
\text { pressure, } \sigma_{3}, \mathrm{MPa}\end{array}$ & $\begin{array}{l}\text { Maximum axial } \\
\text { strain, } \varepsilon_{\mathrm{a}}(\max ) \%\end{array}$ & $\begin{array}{l}\text { Maximum lateral } \\
\text { strain, } \varepsilon_{1}(\max ) \%\end{array}$ & $\begin{array}{l}\text { Maximum volumetric } \\
\text { strain, } \varepsilon_{\mathrm{v}}(\max ) \%\end{array}$ \\
\hline 0 & 0.350 & 0.284 & 0.110 \\
5 & 0.459 & 0.477 & 0.137 \\
10 & 0.594 & 0.593 & 0.187 \\
20 & 0.746 & 0.641 & 0.205 \\
30 & 0.853 & 0.662 & 0.253 \\
40 & 0.935 & 0.595 & 0.271 \\
\hline
\end{tabular}

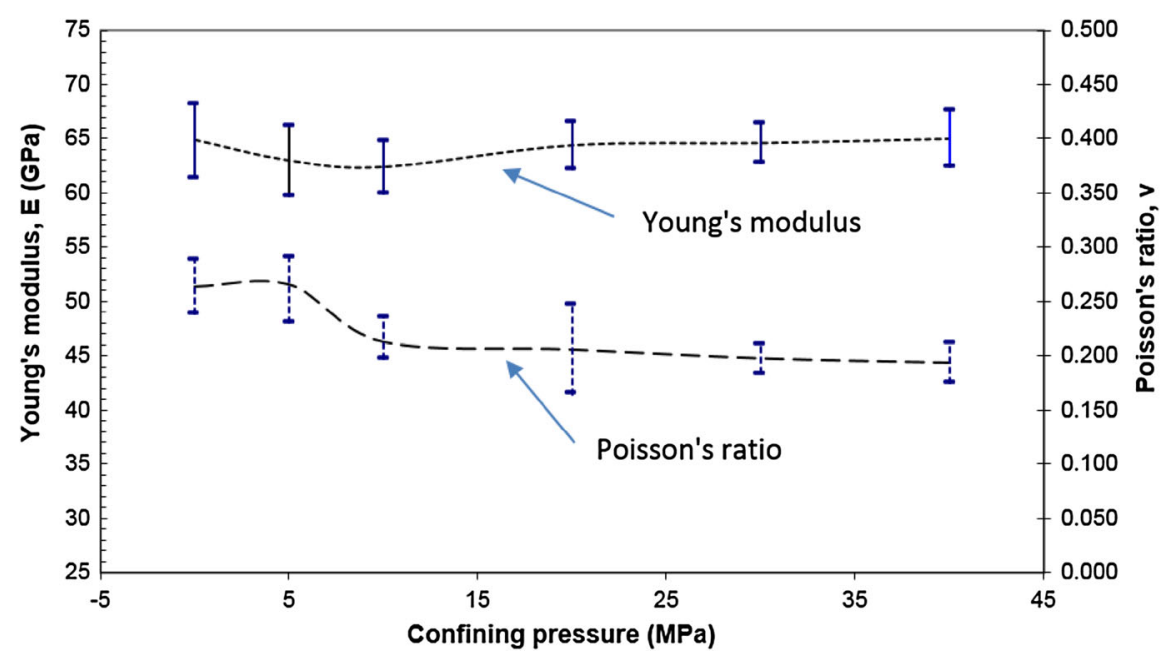

Fig. 7 Effects of confining pressure on Young's modulus and Poisson's ratio of Bukit Timah granite 
5 and $10 \mathrm{MPa}$. For values of confining pressures greater than $10 \mathrm{MPa}$, there is a slight decrease in Poisson's ratio as confining pressure increases.

In order to understand the failure behaviour of Bukit Timah granite under uniaxial and triaxial stress conditions, a comprehensive failure mode analysis was conducted. According to the results, two types of failure modes were observed in most of the specimens tested to failure under uniaxial and triaxial compression. The first type was conical shape failure with slabbing, which happened in uniaxial compression tests, and the second type was wedge-shaped failure with shear plane, which happened in triaxial compression tests. In the uniaxial compression tests, there was a general crumbling caused by the development of multiple cracks (slabbing) parallel to the direction of applied force at the mid-height of the specimen near the surface, as shown in Fig. 8. This is similar to the observation of Fairhurst and Cook (1966). When the specimen collapses, conical end fragments are left, together with long slivers of rock from around the periphery, as shown in Fig. 8. The shearing of the test specimen along a micro oblique plane was observed in most of the specimens in triaxial compression tests, as shown in Fig. 9. The final failure mode of triaxial compression testing is typically a shear failure with a wedge shape. The failure planes ranged from $63^{\circ}$ to $80^{\circ}$, as shown in Fig. 9. The sample loaded up to $0.95 \sigma_{f}$ in triaxial compression condition with confining pressure of $5 \mathrm{MPa}$ showed some traces of vertical cracks parallel to the principal stress direction, as seen

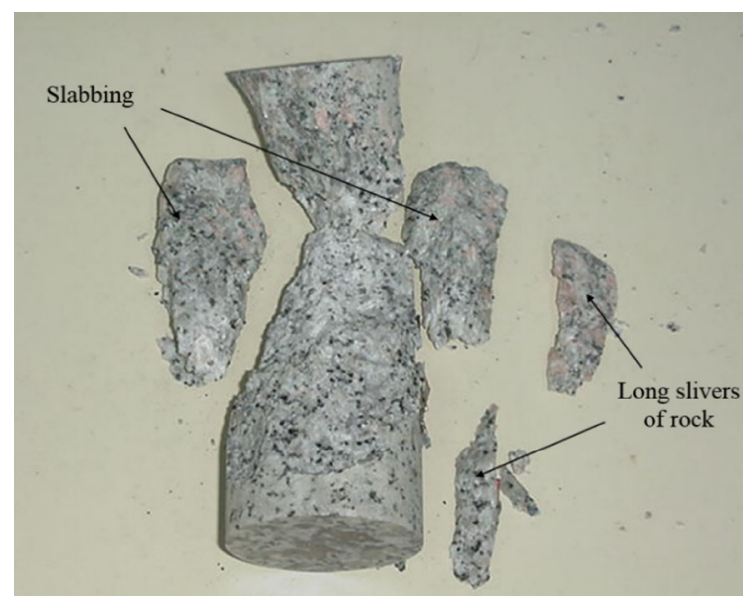

Fig. 8 Conical shape failure at both ends and vertical slabbing on sides of granite specimen in Fig. 10. This axial crack growth has been described as axial cleavage fracture by Gramberg (1989).

Figure 11 shows the effect of water saturation on the compressive strength of Bukit Timah granite under uniaxial stress condition. It is important to note that the total reduction of the average uniaxial compression strength value from dry condition to fully watersaturated condition is about $8 \%$ (Fig. 11). Therefore, it is clear that water saturation has a significant influence on the strength of the granite rock mass, and it probably becomes weaker due to the softening effect of the pore fluid (Dyke and Dobereiner 1991; Erguler and Ulusay 2009; Rathnaweera et al. 2014). This has been clearly shown in past studies, which have shown that water saturation reduces the fracture energy, capillary tension and elastic behaviour and increases the effect of pore pressure and chemical and corrosive deterioration (Hawkins and McConnell 1992; Erguler and Ulusay 2009; Rathnaweera et al. 2014).

Finally, the obtained stress-strain data were used to study the crack formation behaviour of the granite rock mass. According to, Bieniawski (1967a) the stress-strain curves mirror the microscopic activities of brittle rocks, such as crack development and pore closure. Therefore, the stress-strain results were used to analyse the crack propagation and to monitor the various failure stages (crack closure, crack initiation and crack propagation). The stress thresholds of cracking of Bukit Timah granite were determined using the identifying methods summarised in Table 2. Conventionally, stress thresholds can be determined from the axial, lateral and volumetric strain curves, as proposed by Brace et al. 1966 and Bieniawski (1967b). Martin and Chandler (1994) suggested that the crack volumetric strain curve can determine crack initiation $\left(\sigma_{c i}\right)$ in particular, and Eberhardt et al. 1998 used a moving-point regression technique to study the rate of change at each data set point $(x, y=$ stress, strain) from the beginning of deformation to failure. This technique allows the slope to be calculated at each data set point over a user-defined interval and the calculation can be repeated at successive points.

After identifying the appropriate method for determining the stress threshold, stress threshold evaluation was carried out for all the tested confining pressure conditions. However, for simplicity, only the $40 \mathrm{MPa}$ confining pressure condition has been selected for discussion here. According to the analysis, the crack closure region $\left(\sigma_{c c}\right)$ where axial strain shows non- 
Fig. 9 Shear failure of specimens in triaxial compression tests

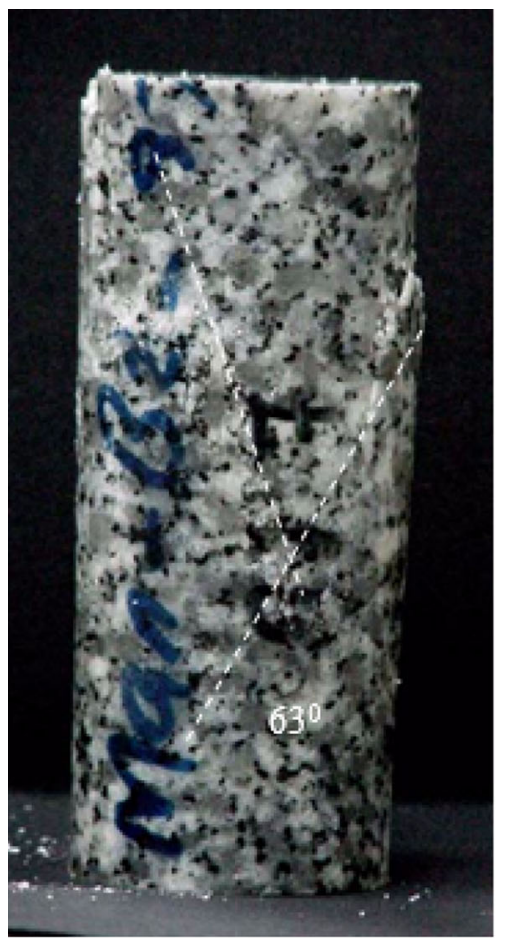

$\sigma_{3}=5 \mathrm{MPa}(\mathrm{TT} 08)$

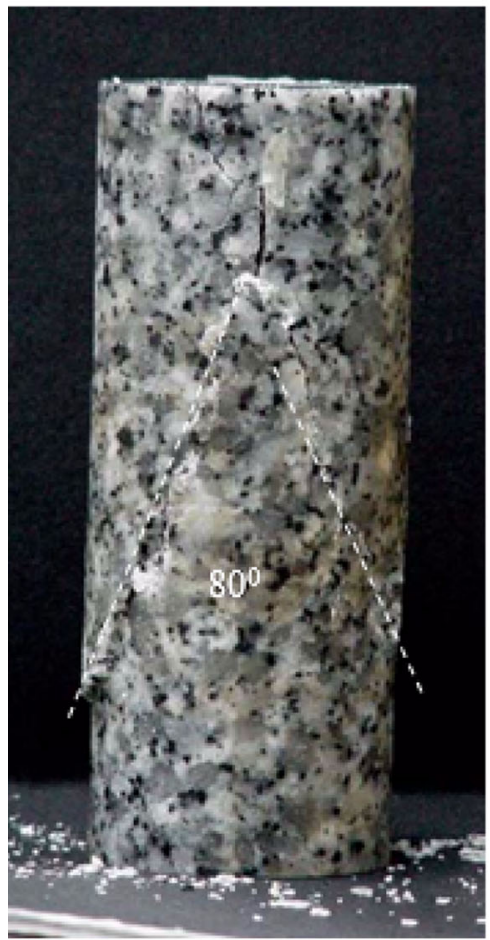

$\sigma_{3}=20 \mathrm{MPa}($ TT22)

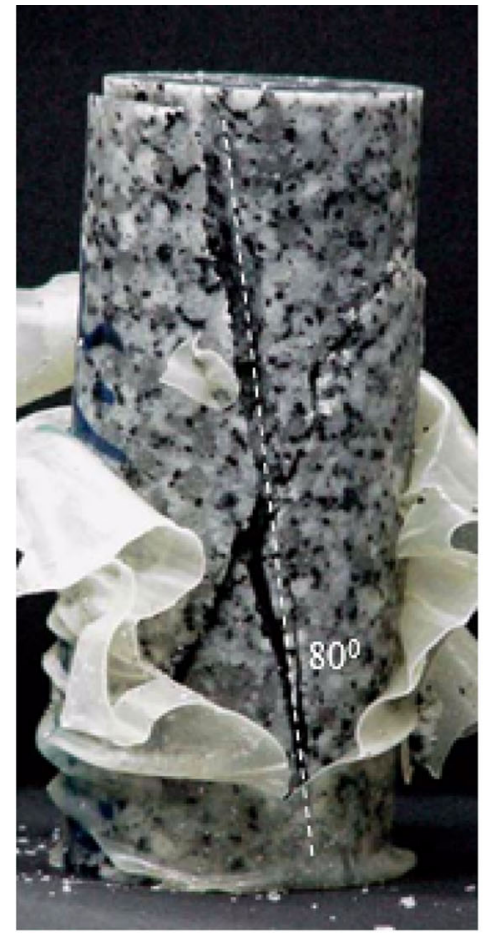

$\sigma_{3}=20 \mathrm{MPa}(\mathrm{TT} 20)$

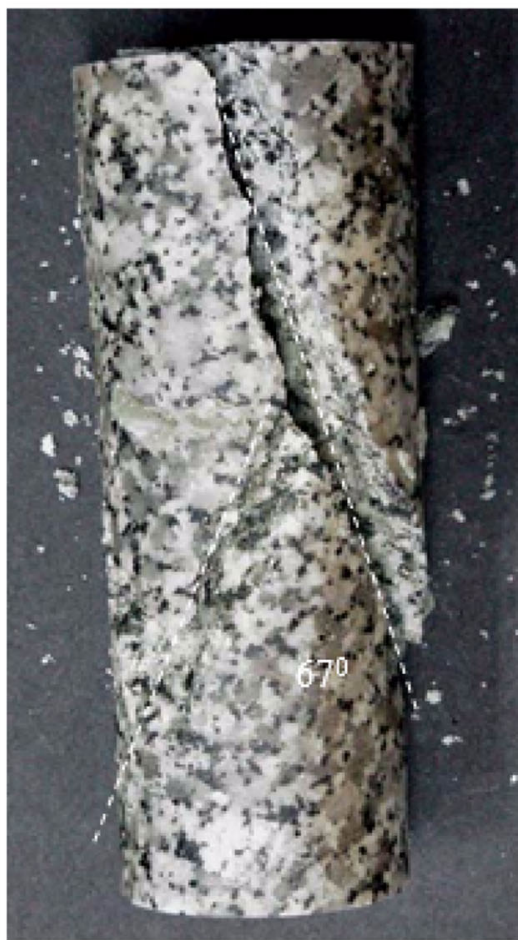

$\sigma_{3}=40 \mathrm{MPa}(\mathrm{TT} 23)$ 


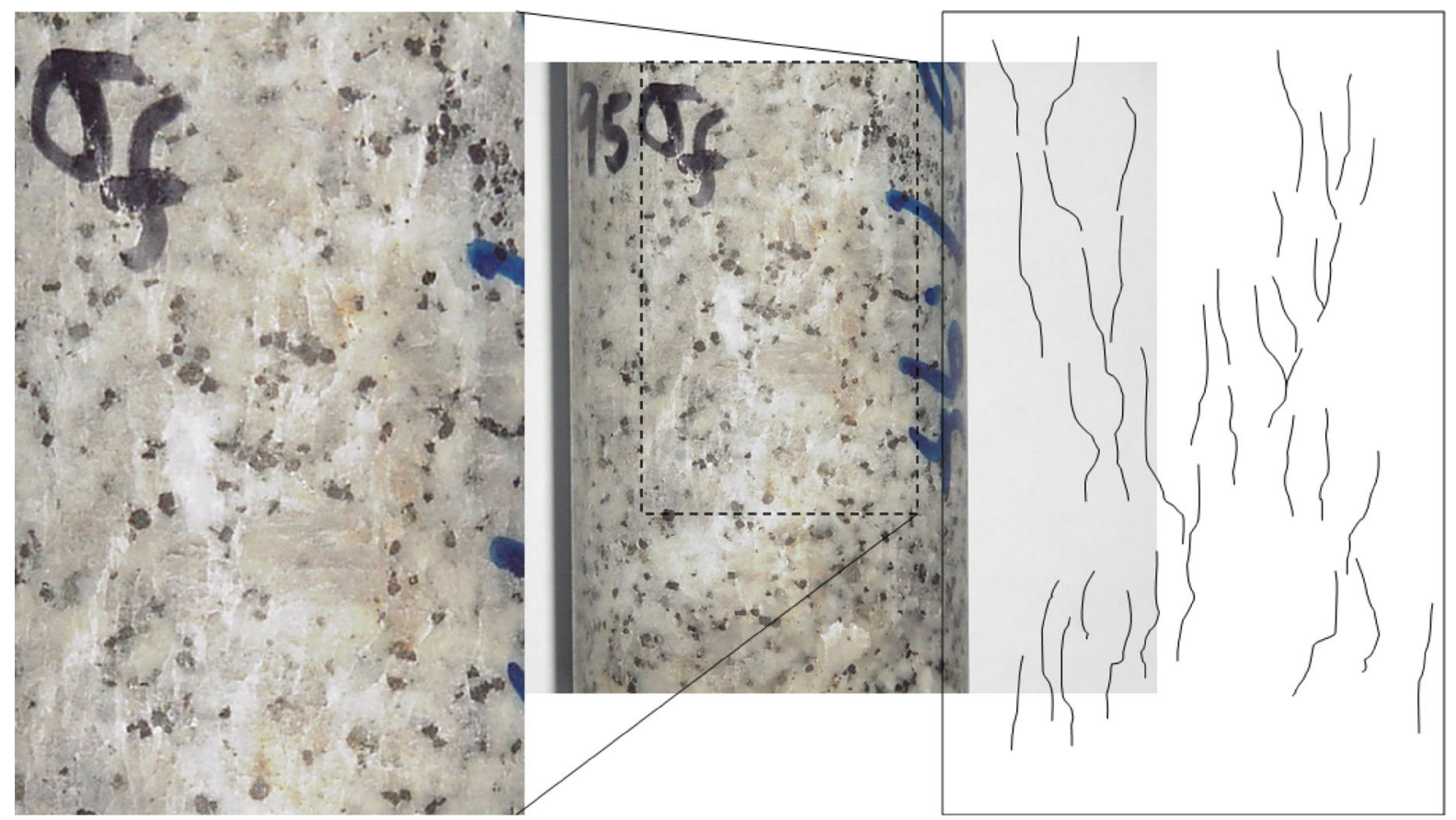

Fig. 10 Forming of shearing of crack propagation coalescence from initially parallel crack growth to loading direction

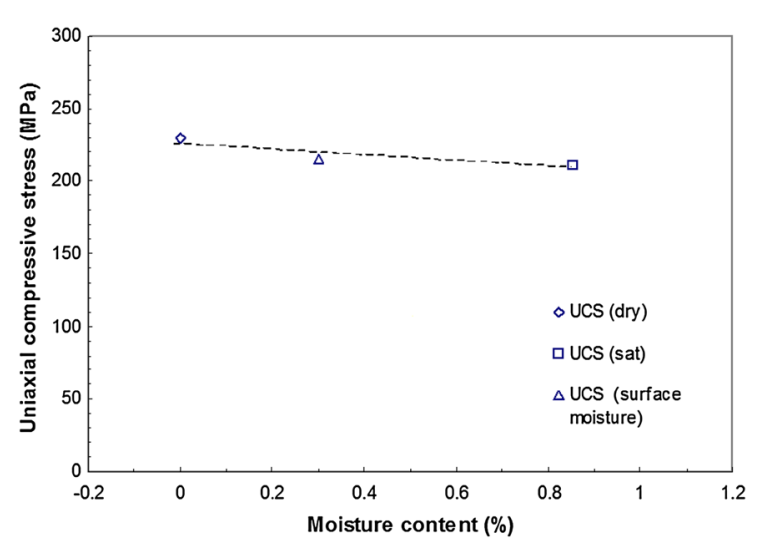

Fig. 11 Reduction of compressive strength due to moisture content

linearity must be observed carefully from the stress-strain curve, as Bukit Timah granite shows very little non-linearity of axial strain during the closure of cracks. However, the average axial stiffness curve calculated using the linear regression technique as shown in Fig. 12 shows clearly that axial stiffness increases slightly at the beginning of loading and reaches a nearly flat zone at the deviator stress level of $160 \mathrm{MPa}$. Here, the point where the axial stiffness curve enters a near elastic region is defined as the crack initiation $\left(\sigma_{c i}\right)$. Brace et al. (1966) and Bieniawski (1967b) proposed that crack initiation starts at the departure of linearity of the volumetric and lateral strain curves, respectively. Using this method, crack initiation was obtained, as shown in Fig. 13. In contrast, Martin and Chandler (1994) suggested that crack initiation can be defined as the stress level at which dilation (crack volumetric strain increase) begins in the crack volume after the closure of all cracks. By applying this method, it can be seen that the specimen begins contraction as soon as the load is applied and reaches the elastic deformation region at an axial strain of $0.060 \%$. Crack initiation started at an axial strain of $0.240 \%$, which corresponds to a crack initiation stress of $160 \mathrm{MPa}$ on the stress-strain graph. In addition, Eberhardt et al. (1998) showed that crack propagation (crack coalescence) can be determined at the start of the relative irregularities region in the volumetric stiffness curve. Therefore, the volumetric stiffness curve was developed based on the results of the $40 \mathrm{MPa}$ confining pressure condition, as shown in Fig. 14. An examination of the volumetric stiffness curve, as proposed by Eberhardt et al. (1998), shows that crack coalescence $\left(\sigma_{c s}\right)$ starts at the departure point of linearity at $251 \mathrm{MPa}$, where larger irregularities occur, as shown in Fig. 14. The crack damage 
Table 2 Some stress threshold identification methods based on stress-strain curve

\begin{tabular}{|c|c|c|c|c|c|}
\hline & $\begin{array}{l}\text { Identifying } \\
\text { methods }\end{array}$ & $\begin{array}{l}\text { Crack closure region } \\
\left(\sigma_{c c}\right)\end{array}$ & Crack initiation $\left(\sigma_{c c}\right)$ & $\begin{array}{l}\text { Crack } \\
\text { coalescence } \\
\left(\sigma_{c c}\right)\end{array}$ & $\begin{array}{l}\text { Crack damage } \\
\left(\sigma_{c c}\right)\end{array}$ \\
\hline \multirow{3}{*}{$\begin{array}{l}\text { Brace (1964), Brace } \\
\text { et al. (1966) and } \\
\text { Bieniawski } \\
(1967 b)\end{array}$} & Axial strain & $\begin{array}{l}\text { Point of non-linear zone } \\
\text { changes to linear zone }\end{array}$ & - & - & - \\
\hline & Lateral strain & - & $\begin{array}{l}\text { Point of departure changes } \\
\text { from linearity to non- } \\
\text { linearity }\end{array}$ & - & - \\
\hline & $\begin{array}{l}\text { Volumetric } \\
\text { strain }\end{array}$ & - & $\begin{array}{l}\text { Point of departure changes } \\
\text { from linearity to non- } \\
\text { linearity }\end{array}$ & - & Point of reversal \\
\hline $\begin{array}{l}\text { Martin and Chandler } \\
\text { (1994) }\end{array}$ & $\begin{array}{l}\text { Crack } \\
\text { volumetric } \\
\text { strain }\end{array}$ & - & $\begin{array}{l}\text { Dilation begins after crack } \\
\text { volume unchanged } \\
\text { during elastic } \\
\text { deformation }\end{array}$ & - & - \\
\hline \multirow[t]{2}{*}{$\begin{array}{l}\text { Eberhardt et al. } \\
\text { (1998) }\end{array}$} & $\begin{array}{l}\text { Axial } \\
\text { stiffness }\end{array}$ & $\begin{array}{l}\text { Point shifting from } \\
\text { incrementally- } \\
\text { increasing value to } \\
\text { constant values }\end{array}$ & - & - & - \\
\hline & $\begin{array}{l}\text { Volumetric } \\
\text { stiffness }\end{array}$ & - & $\begin{array}{l}\text { First large break from } \\
\text { linear behaviour }\end{array}$ & $\begin{array}{l}\text { Starting of } \\
\text { larger } \\
\text { irregularities }\end{array}$ & $\begin{array}{l}\text { Stiffness values } \\
\text { changed from } \\
\text { positive to } \\
\text { negative }\end{array}$ \\
\hline
\end{tabular}

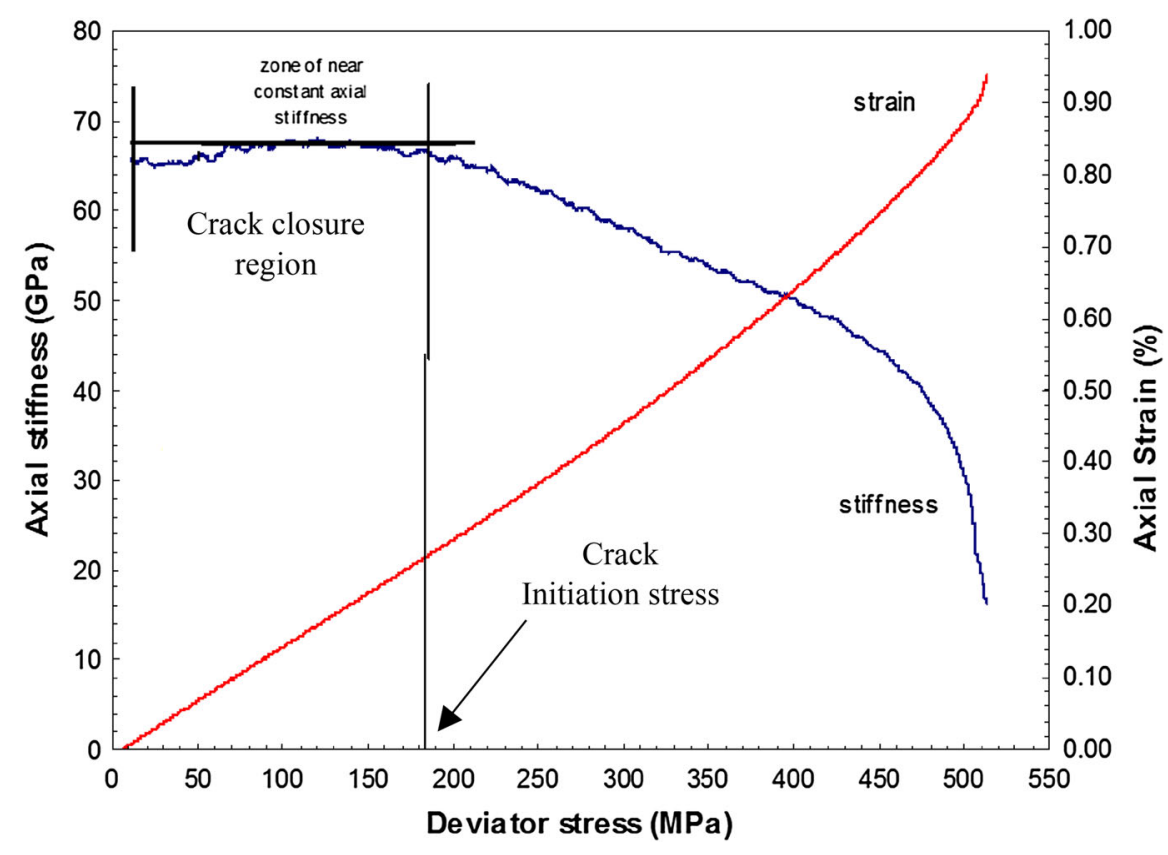

Fig. 12 Axial strain and stiffness curves plotted against deviator stress where axial stiffness is calculated using stress interval range of $8 \mathrm{MPa}$

stress threshold $\left(\sigma_{c d}\right)$ can be determined, as suggested by Bieniawski (1967b), at the point of reversal of the volumetric strain curve, as shown in Fig. 13. For specimens tested under $40 \mathrm{MPa}$ confining pressure, crack damage $\left(\sigma_{c d}\right)$ was found to occur at $356 \mathrm{MPa}$. This reversal of the volumetric strain curve is clearly 
Fig. 13 Stress-strain curve and crack volumetric strain curve of granite specimen with confining pressure of $40 \mathrm{MPa}$

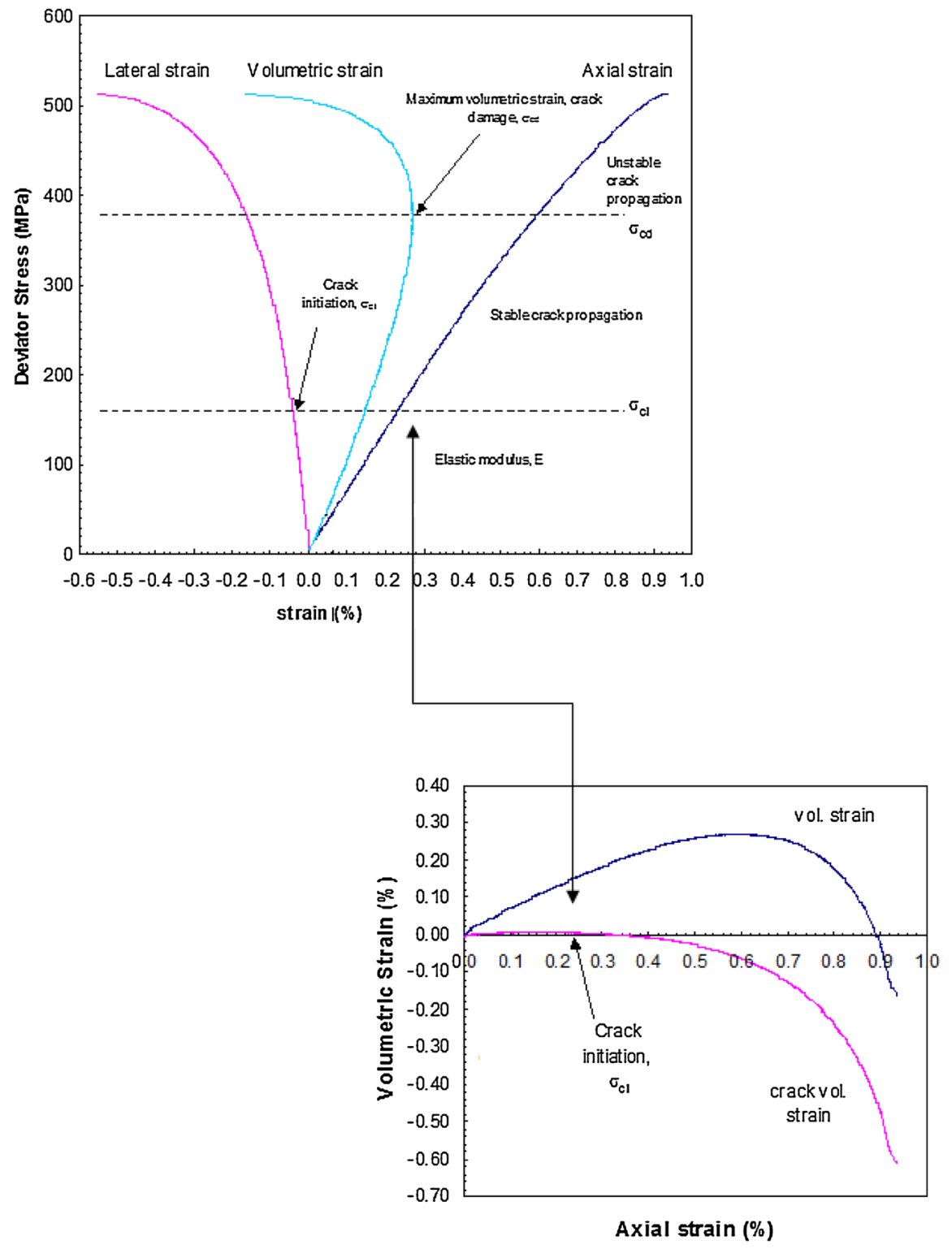

stress under different confining pressures. However, for simplicity, only the $40 \mathrm{MPa}$ confining pressure condition has been selected for discussion purposes (as shown in Fig. 15).

According to Fig. 15, an AE curve can be divided into four distinctive zones based on the gradients: A, $\mathrm{B}, \mathrm{C}$ and D.

\section{Zone A (crack closure region and elastic deformation)}

No significant AE counts (sometimes, small AE counts can be seen due to grain sliding) were detected during 
Fig. 14 Volumetric strain and stiffness curves

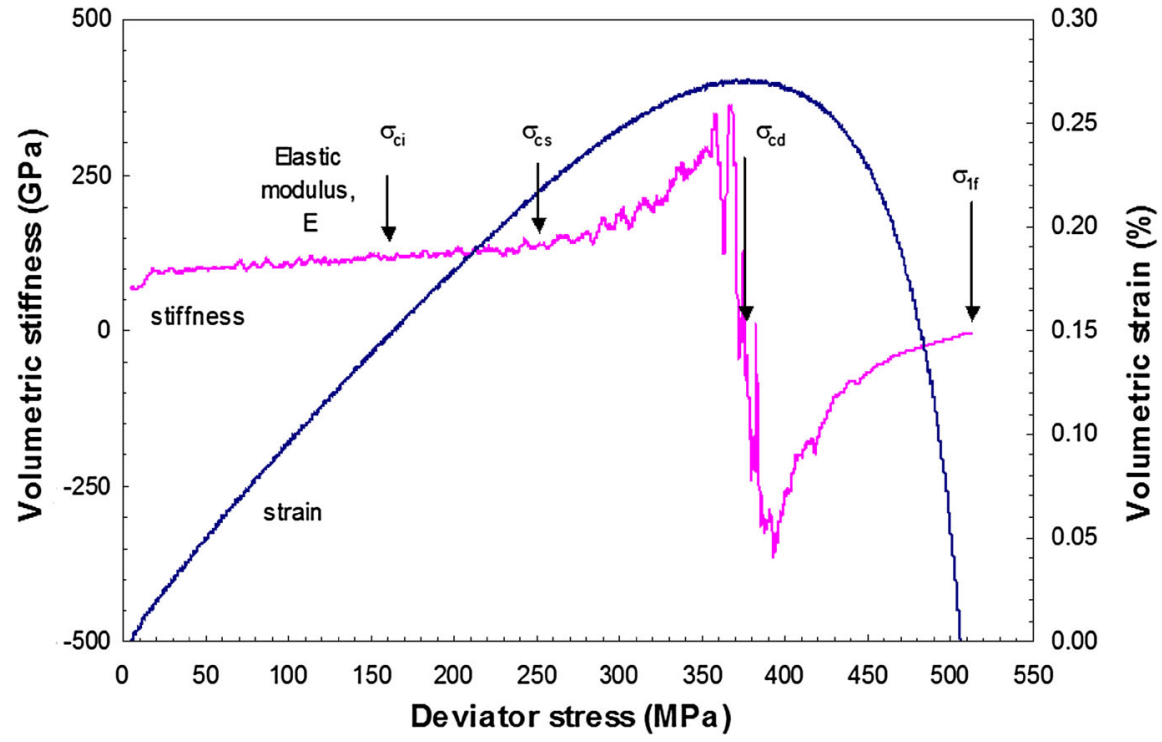

Table 3 Summary of stress thresholds determined from stress-strain curve of Bukit Timah granite

\begin{tabular}{llllll}
\hline $\begin{array}{l}\text { Confining } \\
\text { Pressure, } \\
\sigma_{3}(\mathrm{MPa})\end{array}$ & $\begin{array}{l}\text { Crack closure } \\
\text { region, } \sigma_{\mathrm{cc}}(\mathrm{MPa})\end{array}$ & $\begin{array}{l}\text { Crack initiation, } \\
\sigma_{\mathrm{ci}}(\mathrm{MPa})\end{array}$ & $\begin{array}{l}\text { Crack coalescence, } \\
\sigma_{\mathrm{cs}}(\mathrm{MPa})\end{array}$ & $\begin{array}{l}\text { Crack damage, } \\
\sigma_{\mathrm{cd}}(\mathrm{MPa})\end{array}$ \\
\hline 0 & $0-89$ & 89 & 112 & 156 & $\begin{array}{l}\text { Failure, } \\
\sigma_{1 \mathrm{f}}(\mathrm{MPa})\end{array}$ \\
5 & $0-110$ & 110 & 117 & 177 & 216 \\
10 & $0-121$ & 121 & 158 & 218 & 254 \\
20 & $0-125$ & 125 & 167 & 325 & 408 \\
30 & $0-129$ & 129 & 233 & 356 & 565 \\
40 & $0-150$ & 150 & 251 & 346 \\
\hline
\end{tabular}

the closure of cracks, and similar observations were made by Montoto et al. (1981) for Gondomar and Orense granites. During the tests, AE events were first detected at around $130 \mathrm{MPa}$ in zone A, where sliding is expected to occur.

\section{Zone B (crack initiation and stable crack propagation)}

AE counts increase approximately linearly in zone B (gradient 1) starting at $160 \mathrm{MPa}$, which is marked as crack initiation $\left(\sigma_{\mathrm{ci}}\right)$. Moreover, the linearity of gradient 1 changes where counts start to follow a straight line of a higher slope starting at $250 \mathrm{MPa}$.

\section{Zone $C$ (crack coalescence at stable crack propagation)}

The stress at the start of this linearly increasing $\mathrm{AE}$ count (gradient 2 and zone C) was identified as the crack coalescence $\left(\sigma_{\mathrm{cs}}\right)$. In this linear zone, summations of AE counts increase with loading and depart from linearity again at $370 \mathrm{MPa}$.

\section{Zone D (crack damage and unstable crack propagation)}

The stress at the start of this exponential zone where the linear zone $\mathrm{C}$ in Fig. 15 ends was identified as the crack damage $\left(\sigma_{\mathrm{cd}}\right)$ at $380 \mathrm{MPa}$.

Table 4 summarises the stress threshold values determined by the AE method for Bukit Timah granite. The pattern of observed $\mathrm{AE}$ counts is identical to the Mogi type AE described by Boyce et al. (1981) as having four zones. However, crack coalescence $\left(\sigma_{c s}\right)$ was not identified in his model. On the other hand, Sammonds et al. (1989) found that Zone D could be further divided into two zones, 
Fig. 15 Cumulative AE ring count versus stress for $40 \mathrm{MPa}$ confining pressure

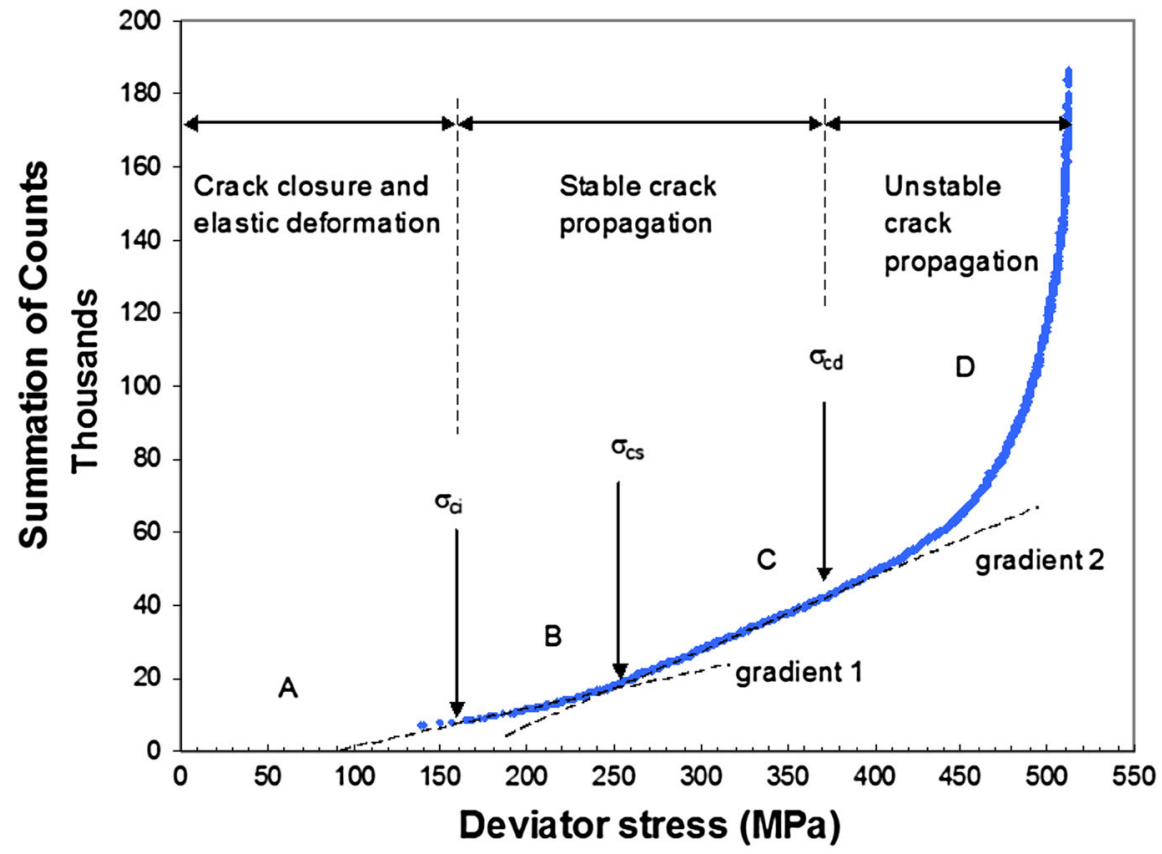

Table 4 Summary of stress thresholds determined from AE method for Bukit Timah granite

\begin{tabular}{lcll}
\hline Confining pressure, $\sigma_{3}(\mathrm{MPa})$ & Crack initiation, $\sigma_{\mathrm{ci}}(\mathrm{MPa})$ & Crack coalescence, $\sigma_{\mathrm{cs}}(\mathrm{MPa})$ & $\mathrm{Crack}$ damage, $\sigma_{\mathrm{cd}}(\mathrm{MPa})$ \\
\hline 0 & 88 & 135 & 158 \\
5 & 106 & 145 & 190 \\
10 & 115 & 163 & 215 \\
20 & 125 & 180 & 270 \\
30 & 138 & 240 & 335 \\
40 & 160 & 250 & 380 \\
\hline
\end{tabular}

namely crack coalescence and frictional sliding on the shear fault zones.

In addition, the $\mathrm{AE}$ counts recorded during testing can be normalised by the total AE counts, as shown in Fig. 16. The trends of AE counts show a uniform pattern, and distinctive stress thresholds can be identified in the same manner as in a specimen tested under $40 \mathrm{MPa}$ confining pressure. In order to clarify the above distinctive trend of the $40 \mathrm{MPa}$ confining pressure sample, the AE count versus deviator stress was further evaluated, as shown in Fig. 17. It is clear from Fig. 17 that the AE count of the first sliding of the mineral is as high as 7000. The counts of the crack initiations and propagations decrease to a residual level of 200 and are concentrated within 10-100 counts. As Fig. 17 shows, $77 \%$ of the AE counts happened after crack damage $\left(\sigma_{c d}\right)$. High AE counts reappear at higher stress levels, especially after $95 \%$ of the failure load. This is similar to the results obtained by Eberhardt et al. (1998).

During the staged loading, the load was held constant for a period of time to observe the AEs at various cracking stress levels, i.e., crack initiation $\left(\sigma_{c i}\right)$, crack coalescence $\left(\sigma_{c s}\right)$ and crack damage $\left(\sigma_{c d}\right)$. An examination of the axial strain curve in Fig. 18 shows that the sample experienced a distinctive crack closure zone. The crack closure region was identified at $0-100 \mathrm{MPa}$, and crack initiation was determined at $100 \mathrm{MPa}$. As it can be seen in Fig. 18 (path A), small numbers of $\mathrm{AE}$ counts were detected at the crack closure region and elastic deformation zones. However, according to the definition of crack closure, crack closure is a region where no strain energy is released and there are therefore are no AE counts. However, 
Fig. 16 Normalised AE count plotted against normalized stress with respective failure strengths

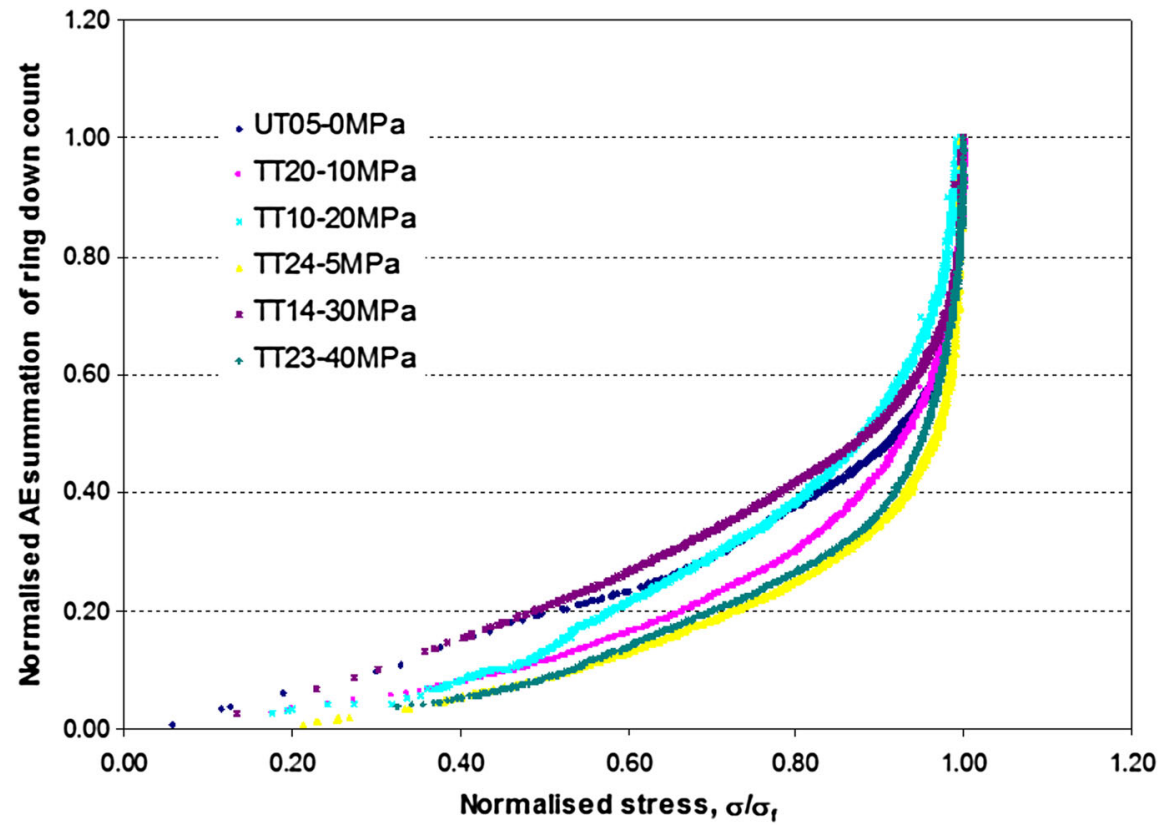

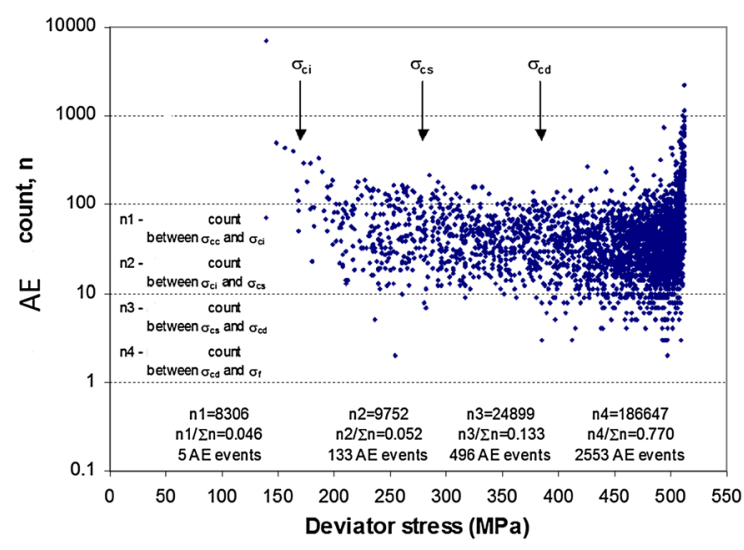

Fig. 17 Ring down counts with loading $\left(\sigma_{3}=40 \mathrm{MPa}\right)$

some energy during the clack closure process can be released due to the grain sliding of the rock grains below the crack initiation stress level and that may be a reasonable explanation for the above observation. During this staged loading, AEs occurred steadily when the load surpassed the previous load level, i.e., crack initiation $\left(\sigma_{c i}=0.45 \sigma_{f}\right)$ at $100 \mathrm{MPa}$, as seen in Fig. 19. In addition, the AEs were found to be dying out, when the load held constant at $0.6 \sigma_{f}$ stress level (stable crack growth zone), as shown in Fig. 20a. Moreover, AEs were observed to occur only when the load surpassed the previously loaded stress level at $0.45 \sigma_{f}$ and $0.60 \sigma_{f}$ in loading paths $\mathrm{A}$ and $\mathrm{B}$,

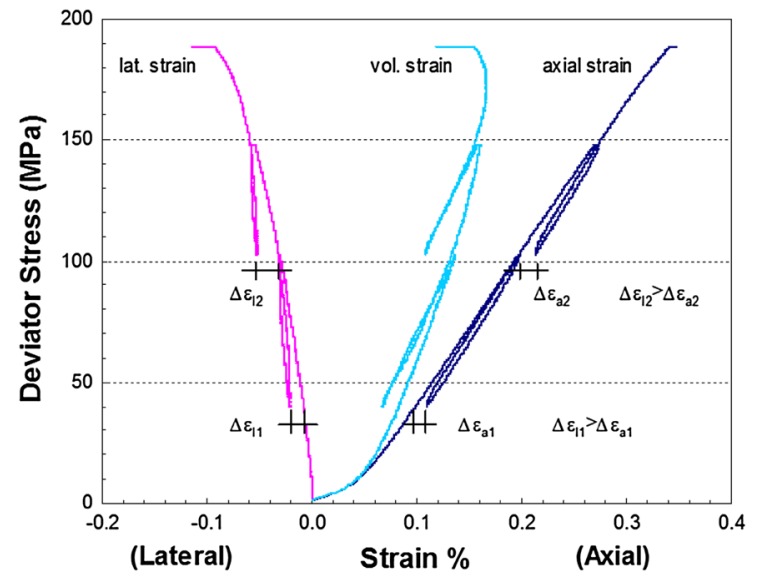

Fig. 18 Stress-strain variation of Bukit Timah granite under staged loading

respectively. This shows that the felicity ratio is $100 \%$ (Kaiser effect) for both the elastic deformation and the stable crack growth zones. During the holding of load at $0.85 \sigma_{f}$, AEs were continuously detected, as shown in Fig. 20b until the specimen failed after $48 \mathrm{~s}$.

\subsection{Petrographical observations}

In order to investigate the cracking mechanisms of crack closure, crack initiation and damage stress threshold leading to failure, thin sections were cut and 


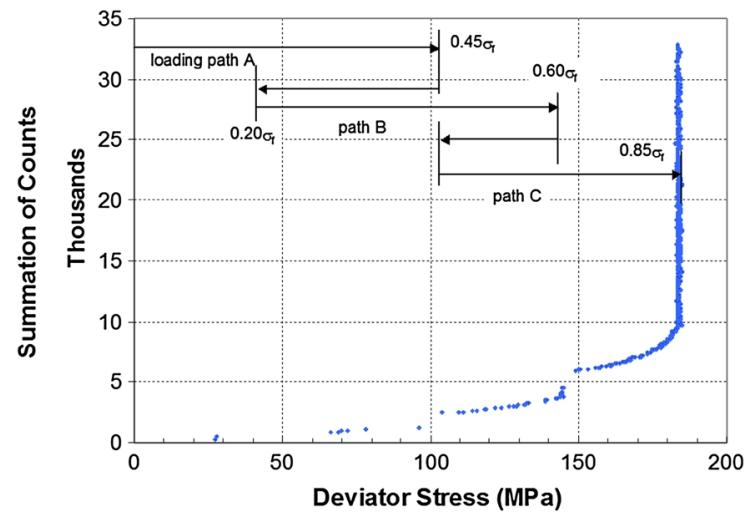

Fig. 19 AE counts versus stress under staged loading of Bukit Timah granite

observed under a petrological microscope and a scanning electron microscope (SEM). Bukit Timah granite specimens were prepared at six and three different loading stages for unconfined and triaxial compression testing, respectively. A summary of the loading stages is shown in Table 5 and the results are summarized in Table 6.

First, it is important to identify the pre-existing cracks with high potentiality of initiating new cracks under loading conditions, so that stress-induced cracks can be recognized easily. From a mineralogical analysis performed under the petrological microscope, specimen BG1 of Bukit Timah granite was identified as a holocrystalline, leucocratic coarse-grained granular rock. It is an acid igneous rock consisting of quartz, biotite, orthoclase feldspar, plagioclase feldspar, hornblende amphibole and secondary alteration products of chlorite, sericite, kaolinite and minor epidote.

Thin sections were prepared from sample BG1 and examined under the petrological microscope and carbon-coated thin sections prepared from the same sample were also examined under the SEM. In the photomicrographs, two types of pre-existing cracks
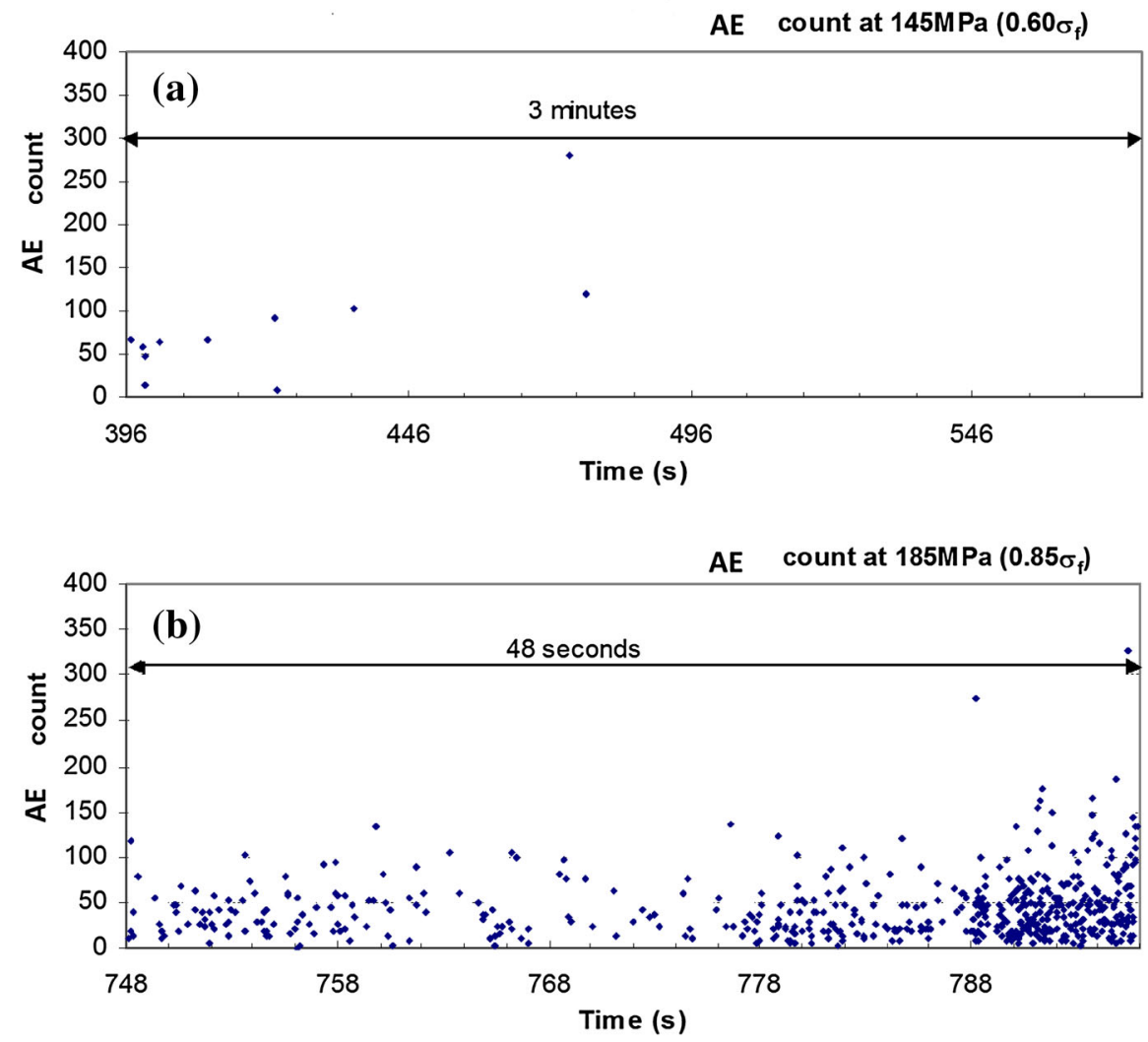

Fig. 20 Ring down counts at a stable crack propagation zones and $\mathbf{b}$ unstable crack propagation zone 
Table 5 Loading stages of Bukit Timah granite specimens for petrographical analysis

\begin{tabular}{lllll}
\hline$\sigma_{3}, \mathrm{MPa}$ & $0\left(\sigma_{f}=214 \mathrm{MPa}\right)$ & $5\left(\sigma_{f}=254 \mathrm{MPa}\right)$ & $20\left(\sigma_{f}=408 \mathrm{MPa}\right)$ & $40\left(\sigma_{f}=546 \mathrm{MPa}\right)$ \\
\hline $0 \sigma_{f}$ (not loaded) & BG1 & & & \\
$0.20 \sigma_{f}$ & BG2 & & & \\
$0.45 \sigma_{f}$ & BG3 & BG8 & BG11 & BG14 \\
$0.60 \sigma_{f}$ & BG4 & & & \\
$0.75 \sigma_{f}$ & BG5 & BG59 & BG12 & BG15 \\
$0.81-0.90 \sigma_{f}$ & BG6 & BG10 & BG13 & BG16 \\
$0.91-1.0 \sigma_{f}$ & BG7 & & \\
\hline
\end{tabular}

are observed, namely inter- and intra-granular cracks. Figure 21 shows the interlocked grain boundary cracks from photomicrograph analysis under crosspolarised light. Generally, these cracks are formed by grain boundaries between the constituent minerals. In addition, Fig. 21 also shows that most grain boundaries are tightly interlocked against one another and a few boundaries may have voids which can be observed using the SEM. Interestingly, three types of intragranular cracks were observed, namely intra-granular veins, cleavages and micro-fissures. Numerous cracks filled with mica minerals were observed within the quartz grain, suggesting that the specimen had an early natural stress history. Similarly, healed fractures have been found in Westerly granite by Moore and Lockner (1995). One of the mica mineral veins is shown in Fig. 22, where the mica minerals show a high degree of birefringence under cross-polarised light. Under plane-polarised light, the same crack is easily seen as well as the grain boundaries between quartz minerals.

Another important feature observed in this photomicrograph is cleavage. Cleavage is the physical property of minerals which may be a weakness plane where a crack might initiate and propagate under loading conditions (Tapponnier and Brace 1967). According to the analysis, simple twinning and some cleavages were shown in the feldspar grain, as indicated in Fig. 23. The cleavage plane was found to be at an angle of $60^{\circ}$ with respect to the centre vertical line. The third type of intra-granular cracks is micro-fissures. Some micro-fissures were observed in the non-loaded specimen (BG1) as being irregular in shape and disorientated (refer to Fig. 24).

When the pre-existing cracks had been identified, a complete set of photomicrograph and SEM analyses was carried out under uniaxial and triaxial loading conditions. Based on the observation of the petrological and SEM images, most of the cracks caused by laboratory-induced stress are long, relatively straight and narrow, with sharp ends, as shown in Fig. 25. These are in contrast to natural cracks, which are blunt, bridged and discontinuous, as shown by Tapponnier and Brace (1967). Two types of stress-induced cracks were observed and grouped as follows: (1) intergranular cracks, which initiate and propagate from the grain boundary, (2) intra-granular cracks, which initiate and propagate within the mineral grain.

According to Hoek (1968), under uniaxial loading conditions, once the stress concentration has overcome the interlocking cohesion in the grain boundaries between mineral grains or exceeded the tensile strength of mineral grains at the tip of cracks, sliding or crack initiation may occur. Generally, cracking initiates at the most favourable angle where the highest stress concentration is induced. As observed in this study (Fig. 26), sliding may occur along the grain boundary below the crack initiation stress level and cracking initiates and propagates into another mineral aligned with the loading direction at the higher stress level. Figure 27 shows that cracking initiates and propagates from the grain boundary healed by mica minerals between quartz and plagioclase. According to Fig. 27, the crack is straight and becomes narrower as the crack propagates in the stress direction.

Figure 28 shows that cracking is initiated in quartz grains from the mica mineral-filled veins and propagates in the direction aligned to the principal stress. This crack resembles Griffith's crack, where cracking is initiated near the crack tip and out of the crack plane. However, this slight overlapping crack geometry does not exhibit internal wing cracks and internal secondary cracks, as postulated by Bobet and Einstein (1998). In 
Table 6 Summary of photomicrograph analysis under uniaxial and triaxial stress conditions

\begin{tabular}{lll}
\hline Loading condition & Remark \\
\hline $\begin{array}{l}\text { Uniaxial } \\
\text { At } 0.20 \sigma_{f}(\mathrm{BG})\end{array}$ & $\begin{array}{c}\text { Stress-induced cracks are not found at this } \\
\text { stress level }\end{array}$
\end{tabular}

At $0.60 \sigma_{f}$ (BG4) Initiation of intra-granular cracks from the pre-existing

micro-fissures is observed

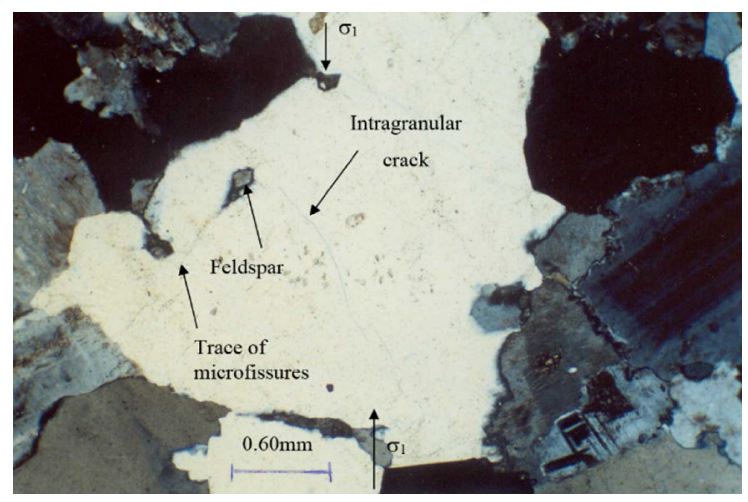

At $0.75 \sigma_{f}$ (BG5) Inter-granular crack propagates from the boundary between quartz and K-feldspar

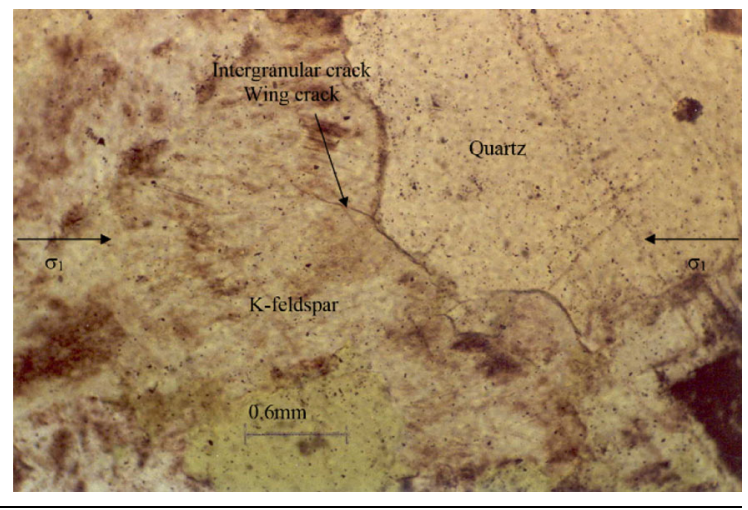


Table 6 continued

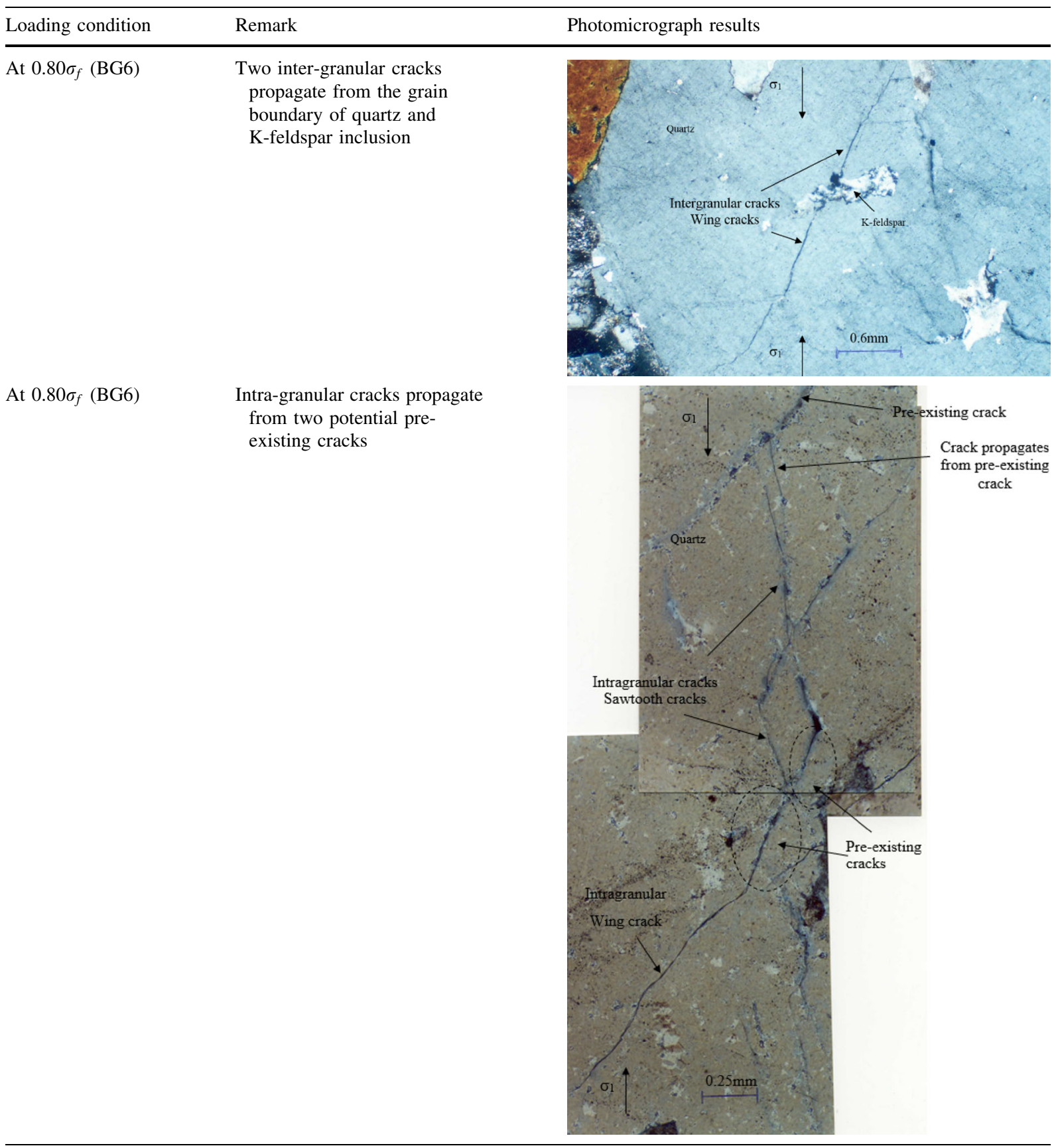


Table 6 continued

\begin{tabular}{|c|c|c|}
\hline Loading condition & Remark & Photomicrograph results \\
\hline \multirow{2}{*}{$\begin{array}{l}\text { Triaxial } \\
\text { At } 0.60 \sigma_{f} \text { (BG8) }\end{array}$} & & \\
\hline & $\begin{array}{l}\text { Initiation of intra-granular cracks from } \\
\text { possibly filled micro-fissures were observed } \\
\text { and crack initiation of inter-granular crack } \\
\text { from grain boundary of quartz and } \\
\text { plagioclase also observed }\end{array}$ & \\
\hline
\end{tabular}

At $0.80 \sigma_{f}$ (BG9)

Initiation and coalescence of propagated crack from another crack system with crack growth from mica mineral-filled microfissures observed

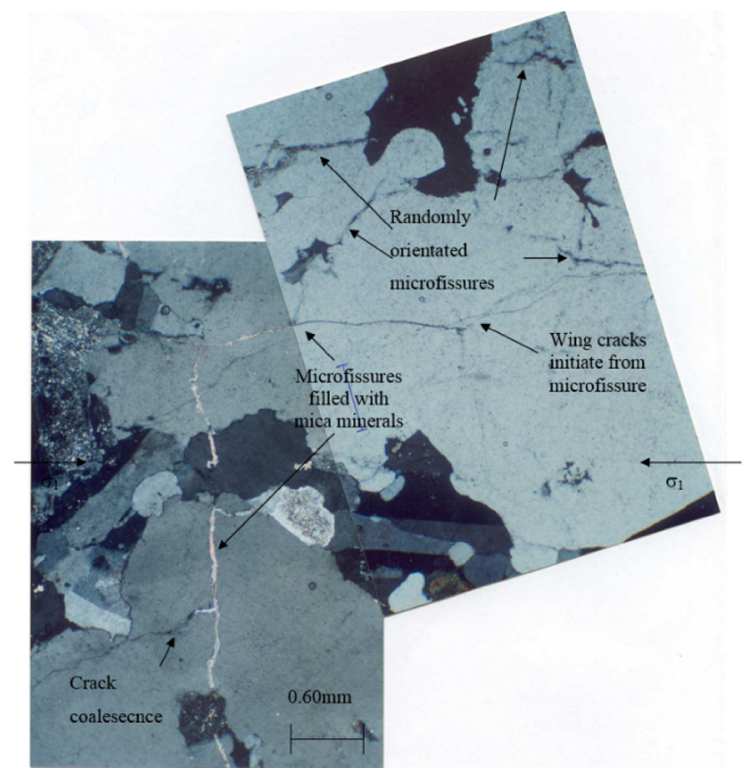


Table 6 continued

\begin{tabular}{|c|c|c|}
\hline Loading condition & Remark & Photomicrograph results \\
\hline At $0.90 \sigma_{f}(\mathrm{BG} 10)$ & $\begin{array}{l}\text { Propagation of crack initiated } \\
\text { from mica-filled micro- } \\
\text { fissures cuts into perthitic } \\
\text { feldspar at } 9^{\circ} \text { to principal } \\
\text { stress direction observed }\end{array}$ & \\
\hline
\end{tabular}


Table 6 continued

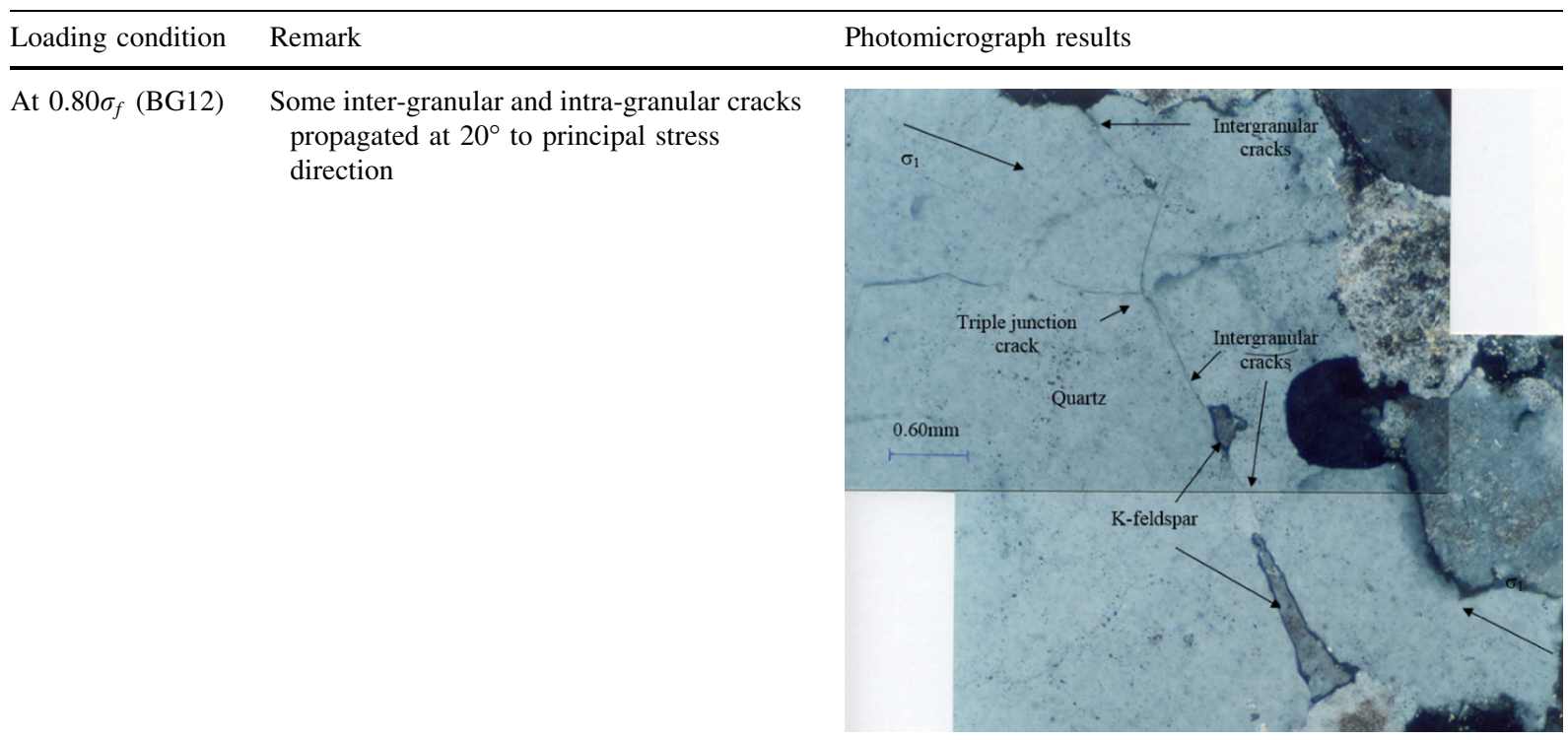

At $0.90 \sigma_{f}$ (BG13) En-echelon crack observed in quartz grain at $35^{\circ}$ to principal stress direction
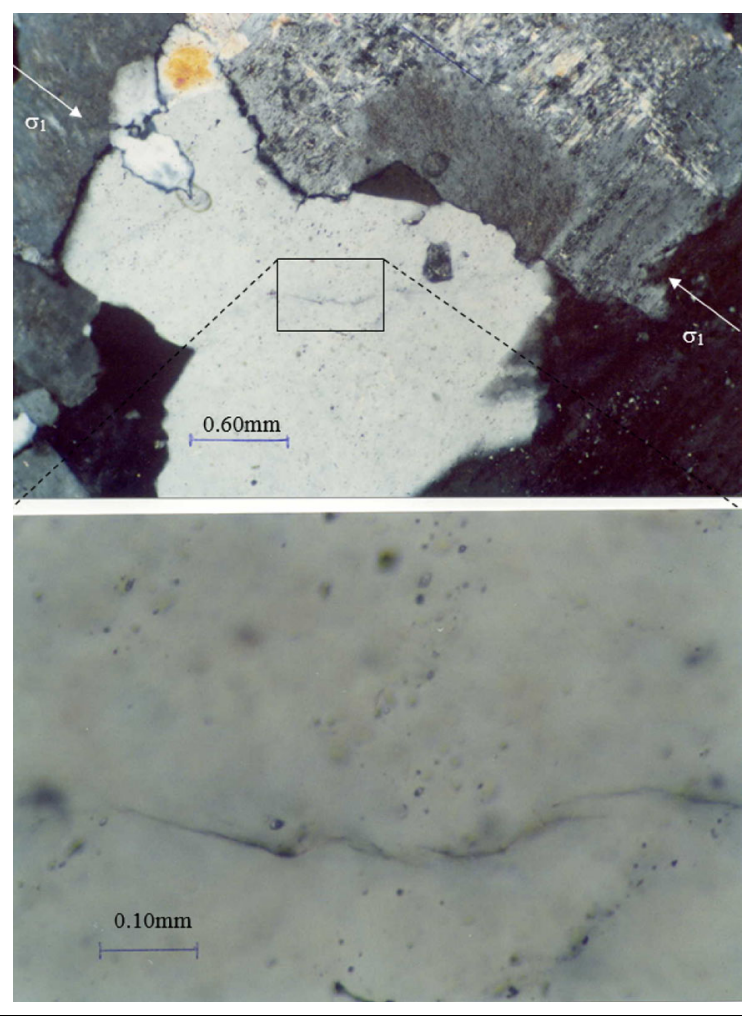
Table 6 continued

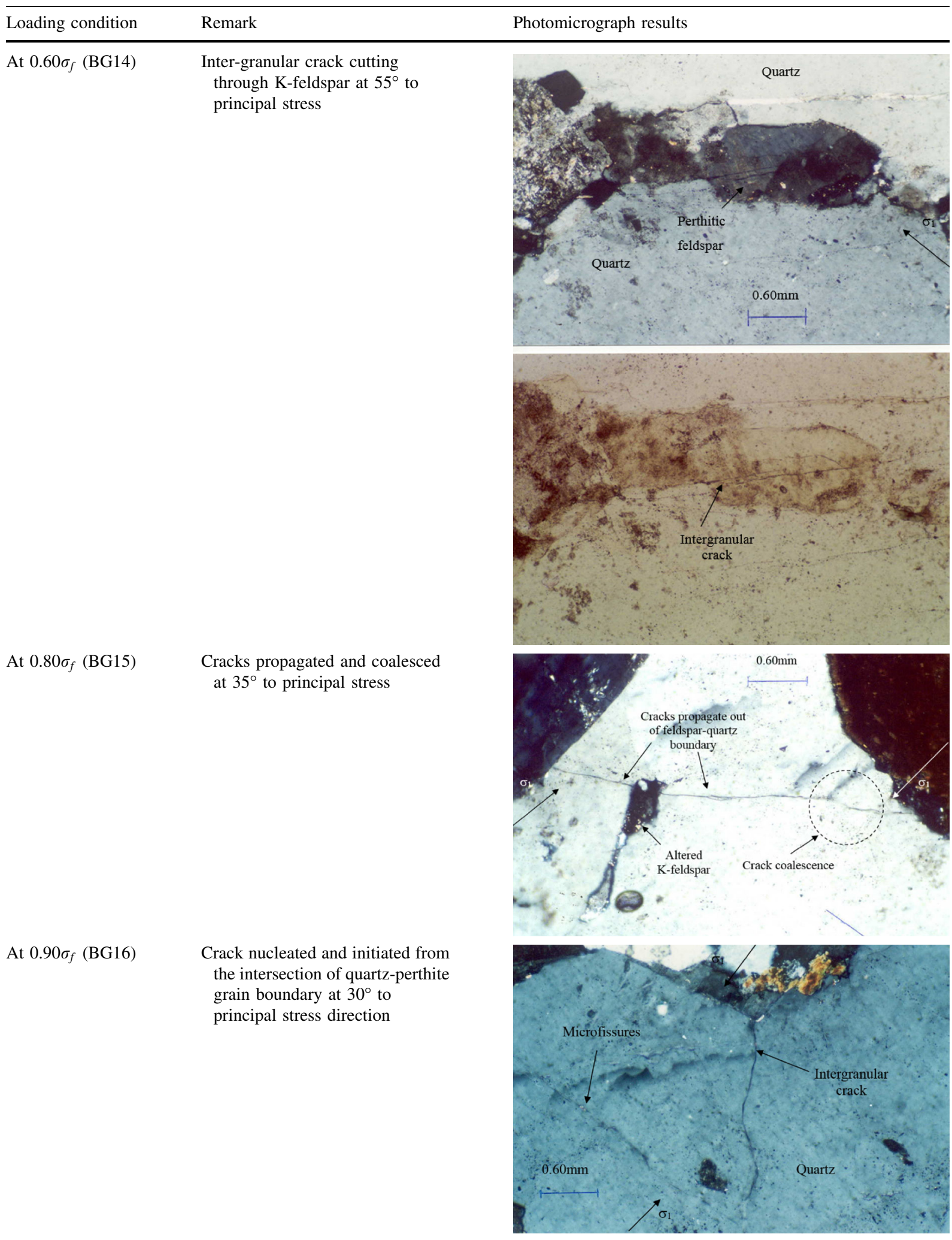




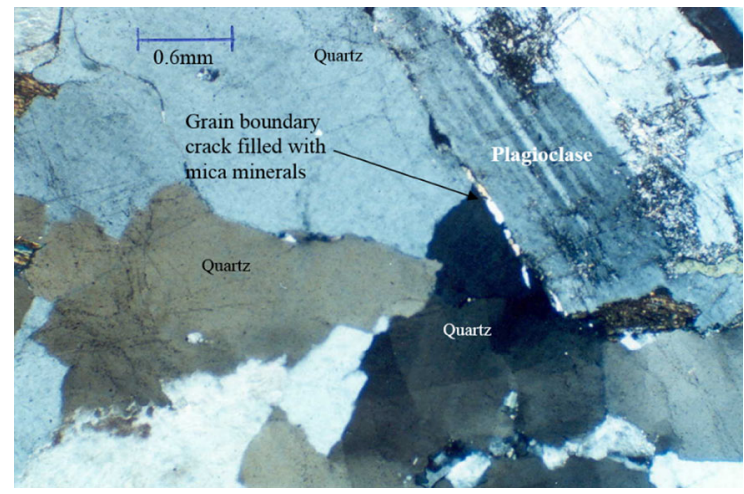

Fig. 21 Photomicrograph of thin section of BG1 under crosspolarised light (XPL)

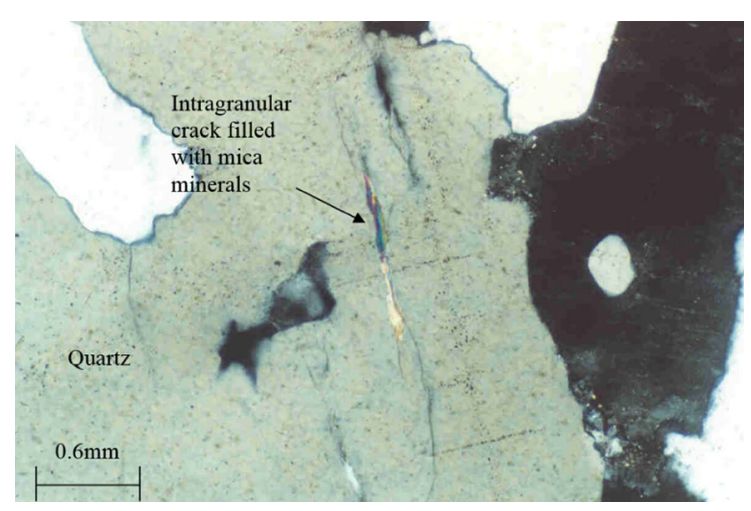

Fig. 22 Photomicrograph of thin section of BG1 vein in quartz filled with mica minerals under cross-polarised light (XPL)

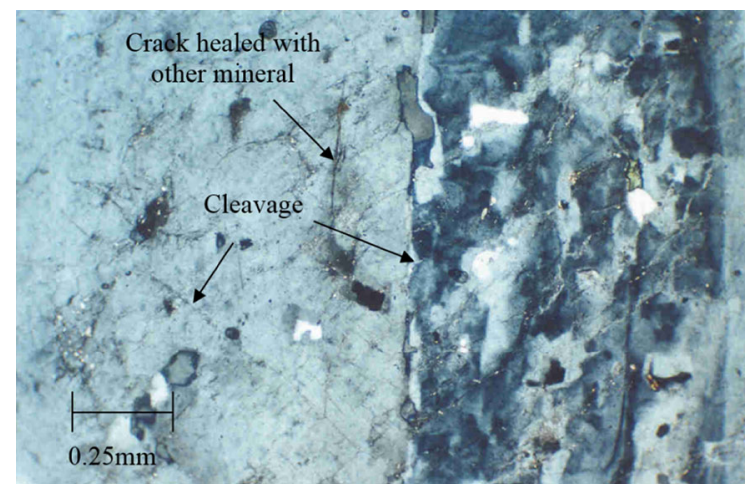

Fig. 23 Photomicrographs of thin section showing simple twinning plagioclase cleavages under cross-polarised light (XPL)

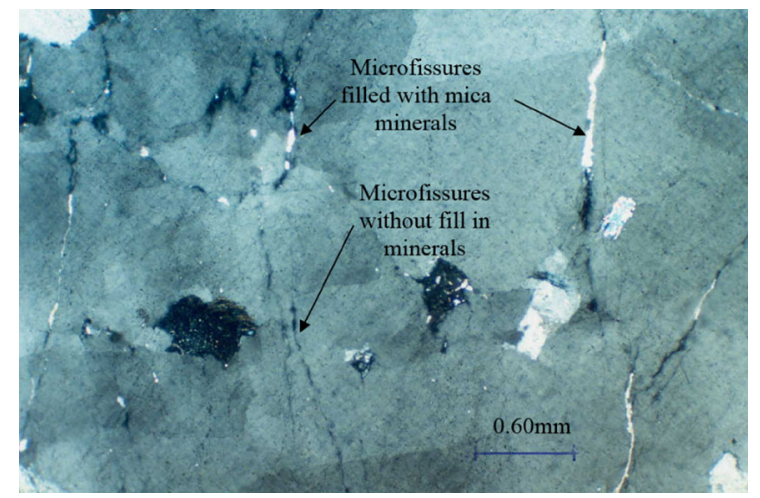

Fig. 24 Photomicrographs of thin section of specimen BG1 showing micro-fissures under XPL

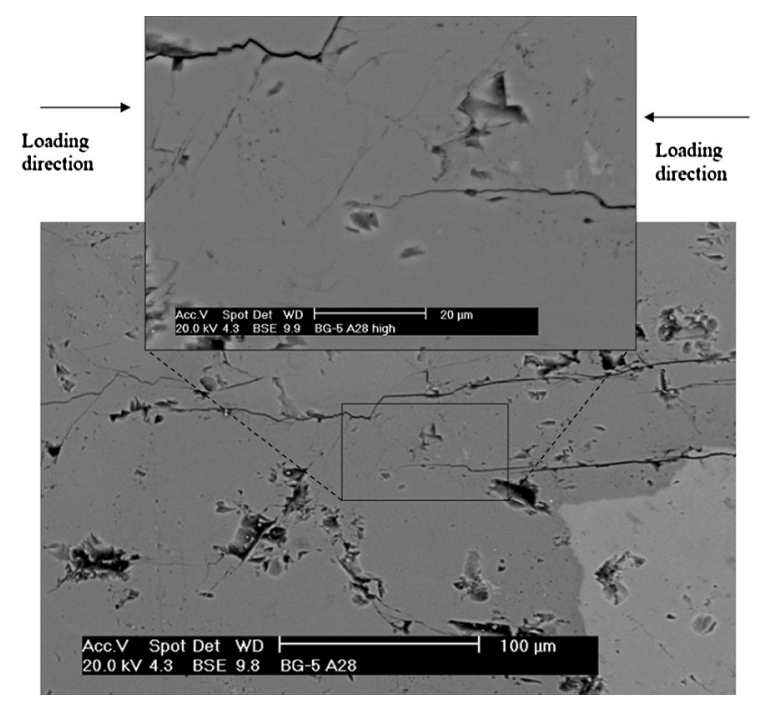

Fig. 25 SEM micrograph showing sharp, narrow initiated shear cracks in BG7 at $0.95 \sigma_{f}\left(\sigma_{3}=40 \mathrm{MPa}\right)$

addition, Fig. 29 illustrates that cracking is initiated from the pre-existing intra-crystal crack or microfissure. From the pattern of crack propagation from initial wing cracking (tensile cracking), progressive propagation of cracking with different phases of loading is clearly shown with a wider crack width narrowing down. Another type of intra-granular cracking is cleavage cracking. According to Fig. 30, wing cracking is initiated from the cleavage plane of biotite, suggesting that cleavage is a potential crack initiation source under loading conditions. 


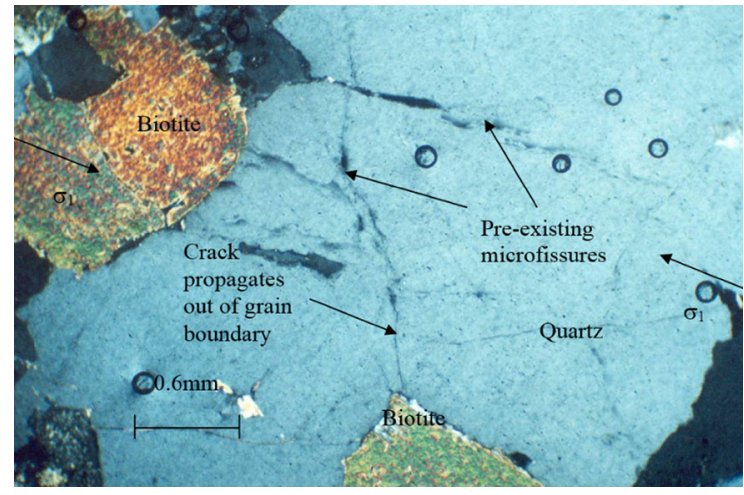

Fig. 26 Photomicrograph of thin section of specimen BG6 at $0.86 \sigma_{f}\left(\sigma_{3}=0 \mathrm{MPa}\right)$ under XPL (crack propagates at $30^{\circ}$ to principal stress direction)

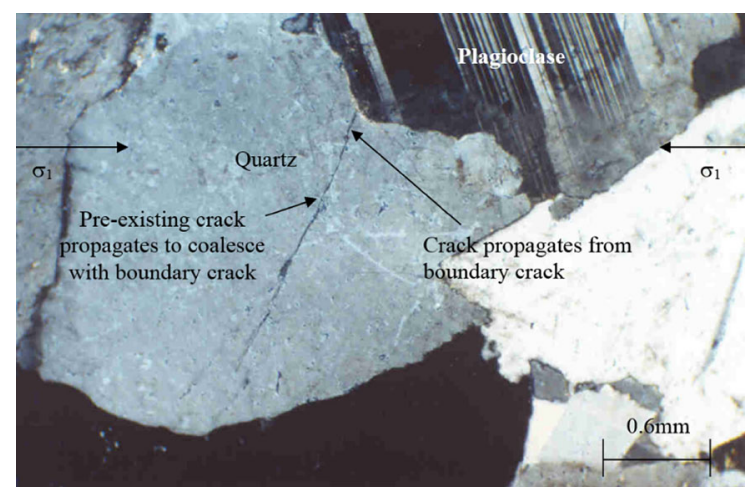

Fig. 27 Photomicrograph of thin section of specimen BG7 at $0.95 \sigma_{f}\left(\sigma_{3}=0 \mathrm{MPa}\right)$ under XPL

\section{Discussion}

During stable crack growth, i.e., after the departure of linearity in crack volumetric strain, the lateral strain rate changes with loading, resulting in the same changes in volumetric strain rate while axial strain rate remains more or less constant. Crack growth is predominantly in the direction of principal stress. As observed in Sect. 4, cracking initiates near the tip of pre-existing healed fractures, as postulated by Hoek (1968), where the tangential stress reaches a limiting value equal to the tensile strength of quartz mineral grains. This crack propagates along a curved path and tends to align itself along the direction of the major principal stress $\sigma_{1}$ as postulated in Griffith's theory. As reflected by crack volumetric strain, these stress-

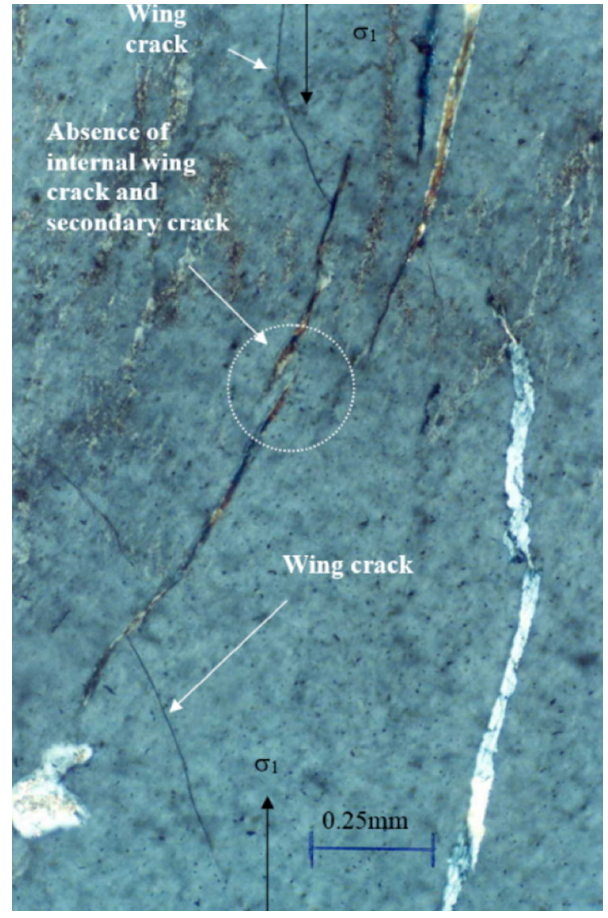

Fig. 28 Photomicrograph of thin section of specimen BG6 at $0.90 \sigma_{f}\left(\sigma_{3}=0 \mathrm{MPa}\right)$ under XPL

induced cracks contribute to the dilatancy of crystalline rocks. Furthermore, the direction of stable crack propagation is reflected in compressibility tests, as suggested by Bieniawski (1967b), as shown in Fig. 18, simply by checking the axial and lateral strain recovery after unloading from the crack initiation stress threshold. The observed narrow cracks, which are perpendicular to the compressive stress, will close, while those parallel to the direction of compression will not close, and consequently, the latter will experience considerably less deformation. In Fig. 18, it can be seen that the lateral compressibility $\left(\Delta \varepsilon_{11}\right)$ is slightly higher than the axial compressibility $\left(\Delta \varepsilon_{a 1}\right)$ after crack initiation has taken place $\left(\Delta \varepsilon_{11}>\Delta \varepsilon_{a 1}\right)$, suggesting that the direction of stable crack propagation is mainly in the vertical direction. A series of such stable propagation cracks initiate from pre-existing cracks, such as the grain boundaries and intra-granular cracks after reaching crack initiation.

In the staged loading shown in Fig. 18, at the onset of crack initiation $\left(0.45 \sigma_{f}\right)$ at $100 \mathrm{MPa}$, AEs are increasing in a linear trend. 


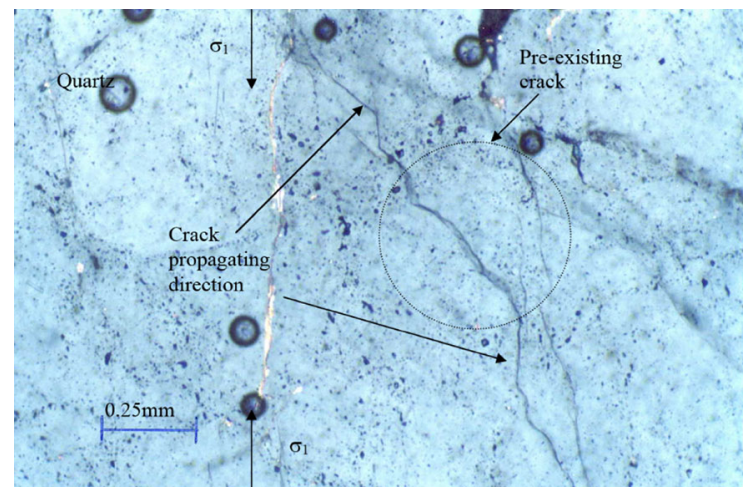

Fig. 29 Photomicrograph of thin section of specimen BG14 at $0.65 \sigma_{f}\left(\sigma_{3}=40 \mathrm{MPa}\right)$ under XPL

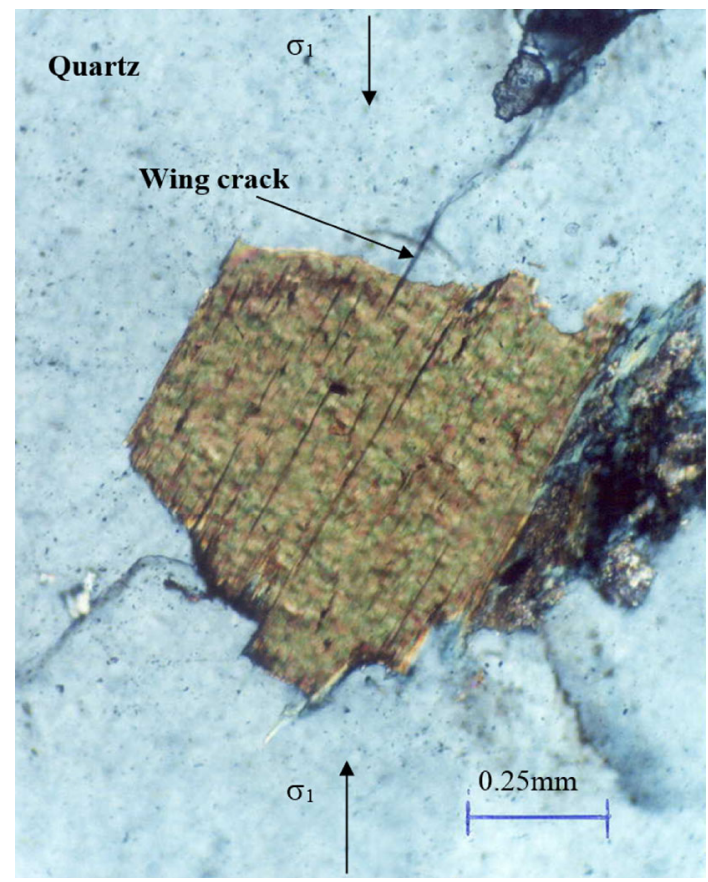

Fig. 30 Photomicrograph of thin section of specimen BG7 at $0.95 \sigma_{f}\left(\sigma_{3}=0 \mathrm{MPa}\right)$ under XPL

Few AEs were detected initially and died out after 2 min while the load was held constant at $148 \mathrm{MPa}$ $\left(0.60 \sigma_{f}\right)$, as shown in Fig. 20a. This proves that stable propagation of cracking is arrested at this stage of loading and crack growth ceases after equilibrium of local stress fields is reached. This confirms the observation of Bieniawski (1967b). The crack damage

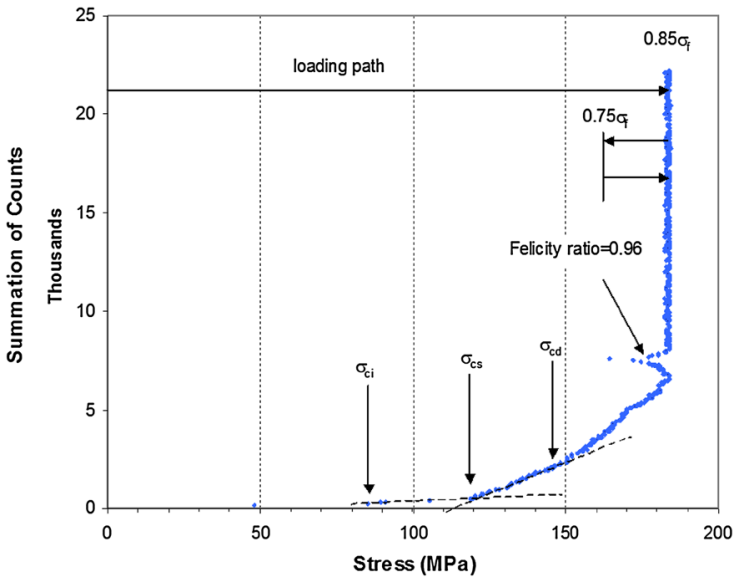

Fig. 31 Stage loading AE results for simple unloading and reloading test $\left(\sigma_{3}=0\right)$

threshold could also be observed by the felicity ratio determined during a simple loading, unloading and reloading process, as in Fig. 31. In the experiments, the felicity ratio was $100 \%$ below $0.60 \sigma_{f}$, and reduces to $96 \%$ at $0.85 \sigma_{f}$, meaning that considerable damage had been done Li and Nordlund (1993) have observed the same effect.

According to the SEM results, three isolated cracking systems were identified where pre-existing cracks are likely to be micro-fissures within quartz grains. As can be seen in Fig. 32, stress-induced cracks propagate initially in a stable manner in a sawtooth shape at an inclined angle to the principal stress direction and eventually develop as sharp wing cracks parallel to the stress. The initially induced cracks appear to have been sheared to some extent and the newly-developed wing cracks are sharp and fine, showing a tendency to coalesce with other wing cracks in an en-echelon pattern. This observation is similar to those of other researchers, including Lajtat et al. (1994), Shen et al. (1995) and Bobet and Einstein (1998).

Based on the petrographical microscope and SEM images, most of the crack initiations occur at the most suitable orientation, as proposed by Griffith (1921). These suitably oriented pre-existing cracks with the maximum induced tangential boundary stress at the crack tip overcome the tensile stress of the material at a certain stage of loading. These crack initiations usually occur at: 
Fig. 32 Images of specimen BG7 at $0.95 \sigma_{f}$ taken under SEM where principal stress $\left(\sigma_{1}\right)$ is in vertical direction

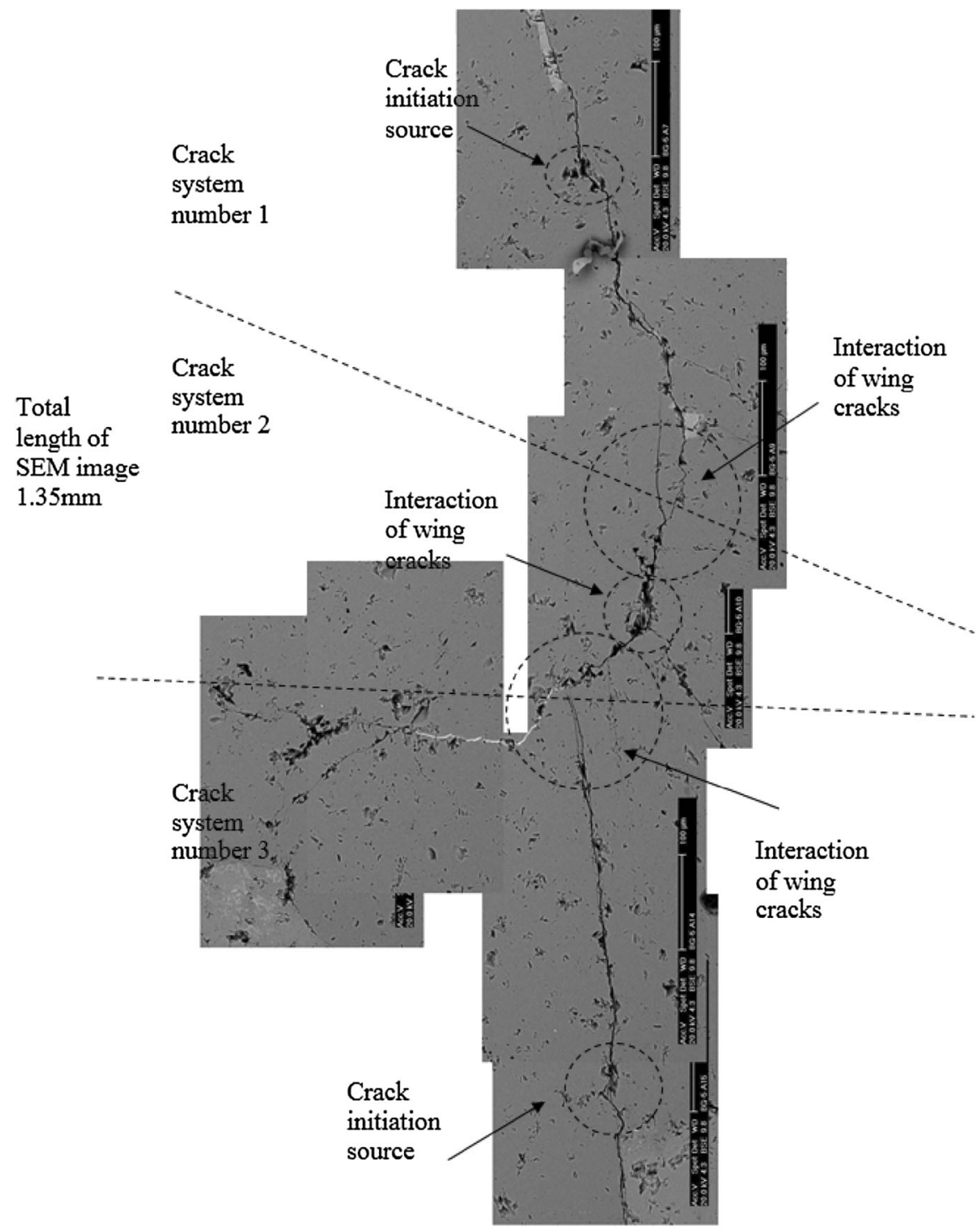

1. Micaeous healed fractures within quartz or feldspar grains.

2. Unhealed pre-existing micro-fissures.

3. Cleavages of biotite or plagioclase.

4. Small grains of K-feldspar inclusions in quartz grains.

5. Inter-granular boundaries of minerals.

These crack initiations are visible with crack propagations aligning to the major principal stress direction under the petrological microscope. The micro-cracks are mostly observed to be growing in response to the increasing applied load, producing axial splitting of the compressed specimen. Axial splitting has also been widely observed by other researchers, including Fairhurst and Cook (1966), Hallbauer et al. (1973) and Stacey (1981).

Table 2 shows the available stress threshold identification techniques based on stress-strain and stiffness curves. According to Brace (1964), Brace et al. (1966) and Bieniawski (1967b), the axial stress versus strain curve can be used to identify the crack closure region in brittle rocks. These researchers define this region as zone where non-linear behaviour transfers into linear behaviour. However, this method has limitations, such as difficulty in clearly identifying the non-linear and linear regions, as observed in the present study (see Fig. 6). If other methods are 
Fig. 33 Comparison of stress thresholds determined by AE technique and stressstrain curve

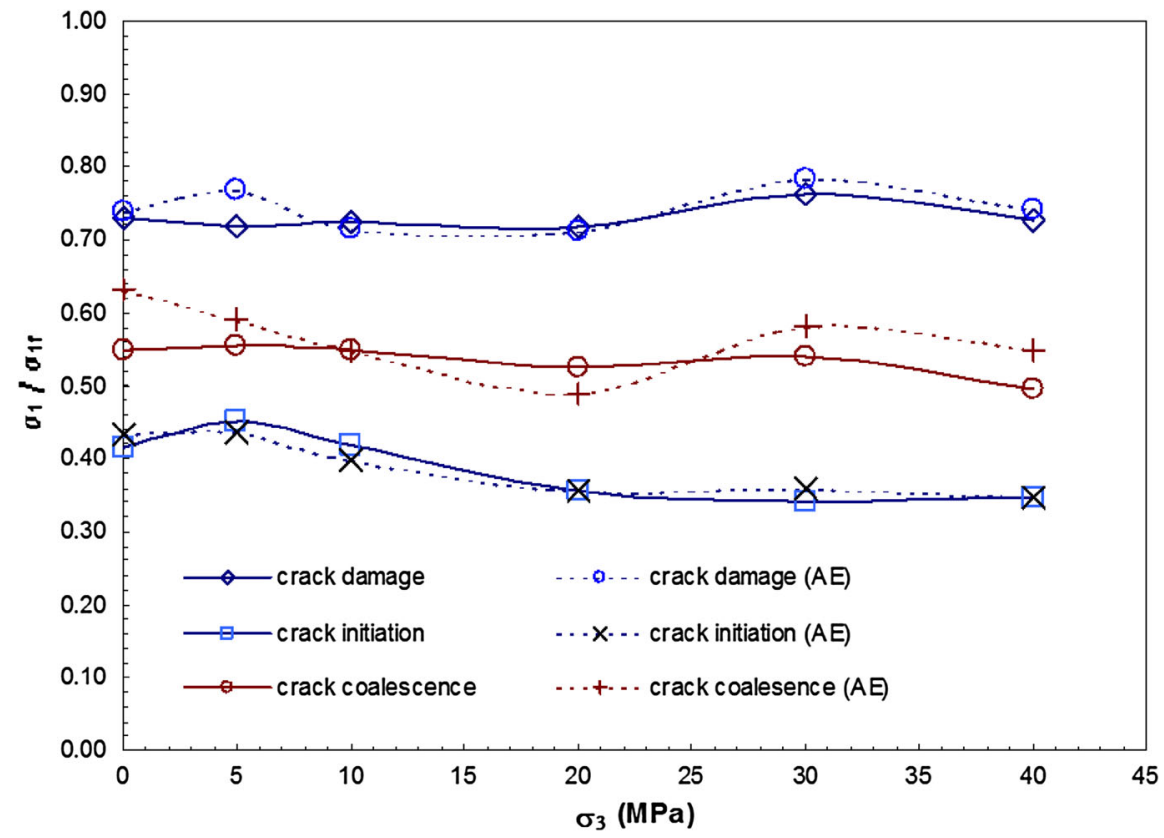

considered (lateral strain, volumetric strain curves), they have the same limitation as mentioned above. Eberhardt et al. (1998) explained the limitations of above methods and stated that the volumetric stiffness method is the most reasonable of all the methods mentioned in Table 2. As explained by Eberhardt et al. (1998), this method can be used to identify the crack closure region and the stress thresholds values in the brittle regime.

Finally, comparisons of crack thresholds determined by stress-strain and AE detection were carried out. Figure 33 shows the relationship between applied confining pressure and the average normalised values of stress thresholds. Both the confining pressure and the stress thresholds were normalised by the failure stresses. Normalised crack initiation determined by stress-strain curve decreases from 0.42 for the uniaxial test to 0.35 at $\sigma_{3}=20 \mathrm{MPa}$ and stabilises beyond $\sigma_{3}=20 \mathrm{MPa}$. A similar trend of crack initiation stress threshold has been found in Lac du Bonnet granite (Martin 1997). Determination of crack initiation by the crack volumetric strain technique shows strong agreement with the detection of AEs. Crack coalescence determined by both methods shows that the normalised stress thresholds consistently fall in the range of 0.50 to 0.60 . However, both methods of stress identification are quite subjective, as shown in the previous sections. On the other hand, crack damage shows a nearly constant ratio of $\left(\sigma_{c d} / \sigma_{f}\right)$ at around 0.75 with all tested confining pressures. Again, Lac du Bonnet granite has also been found to have a similar crack damage stress threshold, as determined by Martin (1997). Both methods show strong agreement with each other. Therefore, it can be concluded that the $\mathrm{AE}$ detection technique is a reliable method to validate the stress thresholds determined by the stress-strain curve approach.

Generally, it is important to evaluate the mechanical behaviour of rocks including stress-strain and cracking mechanisms during the construction of tunnels in order to avoid geological disasters and accidents. Therefore, these types of studies are important for the completeness of the rock database.

\section{Conclusions}

Recent investigations have shown that Bukit Timah granite is a potential rock for hosting rock caverns for both military and civilian uses in Singapore. Therefore, it is essential to investigate the engineering properties and behaviour of the rock in greater detail. In this laboratory study, uniaxial and triaxial compression tests as well as tensile tests were performed. During these tests, the fracturing characteristics of Bukit Timah granite were monitored by means of the AE detection 
technique, and were observed and analysed using a petrographical approach. The following conclusions on Bukit Timah granite can be drawn.

- Examination of axial stiffness is the best way to determine the crack closure region. During crack closure and elastic deformation, only a few sliding events between the crack faces emitting elastic stress waves as AEs were detected, showing that Bukit Timah granite has a high degree of compactness and little sample disturbance.

- The crack volumetric strain approach is proven to be a more precise method to identify crack initiation. Furthermore, the results of the AE detection technique are consistent with those of the crack volumetric strain approach. Staged loading in uniaxial testing revealed that stable crack propagations cease or are arrested at the intermediate load between crack initiation and crack damage.

- Crack damage is best determined at the reversal point of the volumetric strain curve. Unstable crack propagation beyond crack damage is explained by staged loading.

- $\mathrm{AE}$ detection in the staged loading in uniaxial compression testing is proven to be a qualitative method for determining the phenomena of stable and unstable crack propagation.

- Two types of pre-existing cracks are observed under the petrological microscope: inter- and intragranular cracks. Inter-granular cracks are referred to as grain boundaries, whereas intra-granular cracks include healed micro-fissures, unhealed micro-fissures and cleavages of biotite and plagioclase.

- Crack development of pre-existing cracks in Bukit Timah granite is found to be more complicated than in gypsum plaster. However, crack coalescence of wing cracks (tensile cracks) of different isolated crack systems is the main source of the disintegration of specimens.

\section{References}

Bieniawski ZT (1967a) Mechanism of brittle fracture of rock. Part 1. Theory of the fracture process. Int J Rock Mech Min Sci 4(4):395-406

Bieniawski ZT (1967b) Mechanism of brittle fracture of rock. Part 11. Experimental studies. Int J Rock Mech Min Sci 4(4):407-423
Bobet A, Einstein HH (1998) Fracture coalescence in rock-type materials under uniaxial and biaxial compression. Int $\mathbf{J}$ Rock Mech Min Sci 35(7):863-888

Boyce GM, McCabe WM, Koerner RM (1981) Acoustic emission signature of various rock types in unconfined compression. In: Acoustic emission in geotechnical engineering practice. ASTM International, pp 142-154

Brace WF (1964) Brittle fracture of rocks. In: Judd WR (ed) International conference on state of stress in the Earth's Crust. American Elsevier Pub Co., New York, pp 111-180

Brace WF, Bombolakis EG (1963) A note on brittle growth in compression. J Geophys Res 68(12):3709-3713

Brace WF, Paulding BW, Scholz C (1966) Dilatancy in the fracturing of crystalline rocks. J Geophys Res 71(16): 3930-3946

Brady BHG, Brown ET (1994) Rock mechanics for underground mining, 2nd edn. Chapman and Hall, Australia, pp 345-398

Drouillard TF (1996) A history of acoustic emission. J Acoust Emiss 14(1):1-34

Dyke CG, Dobereiner L (1991) Evaluating the strength and deformability of sandstone. Eng Geol 24:123-134

Eberhardt E, Stead D, Stimpson B, Read RS (1998) Identification of crack initiation and propagation threshold in brittle rock. Can Geotech J 35:222-233

Erguler ZA, Ulusay R (2009) Water-induced variations in mechanical properties of clay-bearing rocks. Int $\mathrm{J}$ Rock Mech Min Sci 46(2):355-370

Fairhurst C, Cook NGW (1966) The phenomenon of rock splitting parallel to the direction of maximum compression in the neighbourhood of a surface. In: Proceedings of the first congress of the ISRM. Lisbon, pp 687-692

Fonseka GM, Murrell SAF, Barnes P (1985) Scanning electron microscope and acoustic emission studies of crack development in rocks. Int J Rock Mech Min Sci 22(5):273289

Gramberg J (1989) A non-conventional view on rock mechanics and fracture mechanics. A. A. Rotterdam, Balkema

Griffith AA (1921) The phenomena of rapture and flow in solids. Philos Trans R Soc Lond 21:163-198

Hallbauer DK, Wagner H, Cook NGW (1973) Some observations concerning the microscopic and mechanical behaviour of quartzite specimens. Int J Rock Mech Min Sci 10:713-726

Hardy HR (1981) Applications of acoustic emission techniques to rock and rock structures: a state-of-the-art review. In: Acoustic emissions in geotechnical engineering practice. ASTM International, pp 4-92

Hawkins AB, McConnell BJ (1992) Sensitivity of sandstone strength and deformability to changes in moisture content. Eng Geol 25:115-130

Hoek E (1968) Brittle fracture of rock. Rock mechanics in engineering practice. American Society of Testing and Materials, Wiley, London, pp 4-92

Hoek E, Bieniawski ZT (1965) Brittle fracture propagation in rock under compression. Int J Fract Mech 1(3):137-155

Hoek E, Kaiser PK, Bawden WF (1995) Support of underground excavation in hard rock. A. A. Balkema, Balkema

Lajtai EZ, Lajtai VN (1974) The evaluation of brittle fracture in rocks. J Geol Soc Lond 130:1-18 
Lajtat EZ, Carter BJ, Duncan EJS (1994) En echelon crackarrays in potash salt rock. Int J Rock Mech Rock Eng 27(2):89-111

Li C, Nordlund E (1993) Assessment of damage in rock using the Kaiser effect of acoustic emission. Int J Rock Mech Min Sci 30(7):943-952

Martin CD (1997) The effect of cohesion loss and stress path on brittle rock strength. Can Geotech J 34:698-725

Martin CD, Chandler NA (1994) The progressive fracture of Lac $\mathrm{Du}$ Bonnet Granite. Int $\mathrm{J}$ Rock Mech Min Sci 31(6):643-659

McClintock FA, Walsh JB (1962) Friction on Griffith cracks in rocks under pressure. In: Proceedings 4th US international congress on rock mechanics. pp 333-340

Mogi K (1966) Some precise measurements of fracture strength of rocks under uniform compressive stress. Rock Mech Eng Geol 4:41-55

Montoto M, Montoto L, Röshoff K, Leijon B (1981) Microfractographic study of heated and non-heated Stripa granite. In: Bergman M (ed) Subsurface space, proceedings of the 80th international symposium rockstore. Stockholm, pp 1357-1368

Moore DE, Lockner DA (1995) The role of microcracking in shear fracture propagation in granite. J Struct Geol 17(1):95-114

Pitts J (1984) A review of geology and engineering geology in Singapore. Q J Eng Geol 17:93-101

Ranjith PG, Pong SF, Chian W, Haque A (2004) Characterization of fractured rocks under uniaxial loading states. Int $\mathrm{J}$ Rock Mech Min Sci 4:361-372
Rathnaweera TD, Ranjith PG, Perera MSA (2014) Salinity-dependent strength and stress-strain characteristics of reservoir rocks in deep saline aquifers: an experimental study. Fuel 122:1-11

Rathnaweera TD, Ranjith PG, Perera MSA, Lashin A, Al Arifi N (2015) Non-linear stress-strain behaviour of reservoir rock under brine saturation: an experimental study. Measurement 71:56-72

Reyes O, Einstein HH (1991) Failure mechanisms of fracture rock. In: Proceedings of the 7th US national congress of applied mechanics, pp 333-340

Sammonds PR, Ayling MR, Meredith PG, Murrell SAF, Jones C (1989) A laboratory investigation of acoustic emission and elastic wave velocity changes during rock failure under triaxial stresses. In: ISRM International Symposium. International society for rock mechanics, pp 233-240

Shen B, Stephansson O, Einstein HH (1995) Coalescence of fractures under shear stress experiments. J Geophys Res 100(6):5975-5990

Stacey TR (1981) A simple extension strain criterion for fracture of brittle rock. Int J Rock Mech Min Sci 18:469-474

Tapponnier P, Brace WF (1967) Development of stress-induced microcracks in Westerly Granite. Int J Rock Mech Min Sci 13:103-112

Wasantha PLP, Ranjith PG, Zhang QB, Xu T (2015) Do joint geometrical properties influence the fracturing behaviour of jointed rock? An investigation through joint orientation. Geomech Geophys Geo-Energy Geo-Resour 1(1-2):3-14 